\title{
Fatigue assessment of welded joints by means of the Strain Energy Density method: Numerical predictions and comparison with Eurocode 3
}

\author{
P. Foti, S. Filippi, F. Berto \\ Norwegian University of Science and Technology, Norway \\ pietro.foti@ntnu.no,essefilippi@libero.it,filippo.berto@ntnu.no
}

\begin{abstract}
The main aim of the present work is to investigate the effects of different parameters on the fatigue strength of four different welded details through an energetic approach based on the Strain Energy Density failure criteria.

The results of the finite element analyses have been compared with the fatigue strength predicted by the design guidance EN 1993-1-9:2005, also known as Eurocode 3, which establishes the rules for the fatigue design of steel welded joints.

The results obtained in this work highlight an overestimation of the fatigue strength by the Eurocode 3 with regard to the details considered.
\end{abstract}

KEYWORDS. Welding; Strain Energy Density method; Fatigue assessment; Finite element Analysis; Eurocode 3.

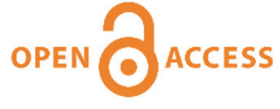

Citation: Foti, P., Filippi, S., Berto, F., Fatigue assessment of welded joints by means of the Strain Energy Density method: Numerical predictions and comparison with Eurocode 3, Frattura ed Integrità Strutturale, 47 (2019) 104-125.

Received: 01.11 .2018

Accepted: 11.11.2018

Published: 01.01.2019

Copyright: (C) 2019 This is an open access article under the terms of the CC-BY 4.0, which permits unrestricted use, distribution, and reproduction in any medium, provided the original author and source are credited.

\section{INTRODUCTION}

$\mathrm{F}$ atigue is the progressive structural damage due to the application of cyclic loads with variable-amplitude. Fatigue in welding components is a much more complex phenomenon because of the welding process itself that involves heating and cooling processes, a different filler material with the consequent inhomogeneity of the joint, residual stresses, undercuts, inclusion and many other defects and imperfections.

As regards the welded joints, the standards take into account assessment methods mainly based on the nominal stress approach [1-3] even if the nature of fatigue phenomenon is local. The nominal stress method considers external loads or nominal stresses in the critical cross-section and compares them with the S-N curves that correlate the fatigue strength, expressed either by the amplitude or the range of the nominal stress or by the remotely applied loads (especially when nominal stresses cannot be easily defined), versus the number of cycles.

As a result, this method overcomes the local nature of the problem including the influence of all the peculiarities that characterise a welded joint in the nominal S-N curves. From a theoretical point of view, this also means that the fatigue behaviour of a component is considered only in a statistical way and that each curve, obtained through experimental data, should be used only for the particular detail analysed with the fatigue tests. 
In order to obtain a more general method, through a huge number of tests with a $75 \%$ confidence level of $95 \%$ probability of survival, the standards define the so-called FAT classes that represent the permissible value of the nominal stress ranges at 2 million of cycles for the joint considered. For the standards, this is enough to characterise the fatigue behaviour of several different details because of the assumption that the components Wohler curves have the same inverse slope in a bilogarithmic diagram.

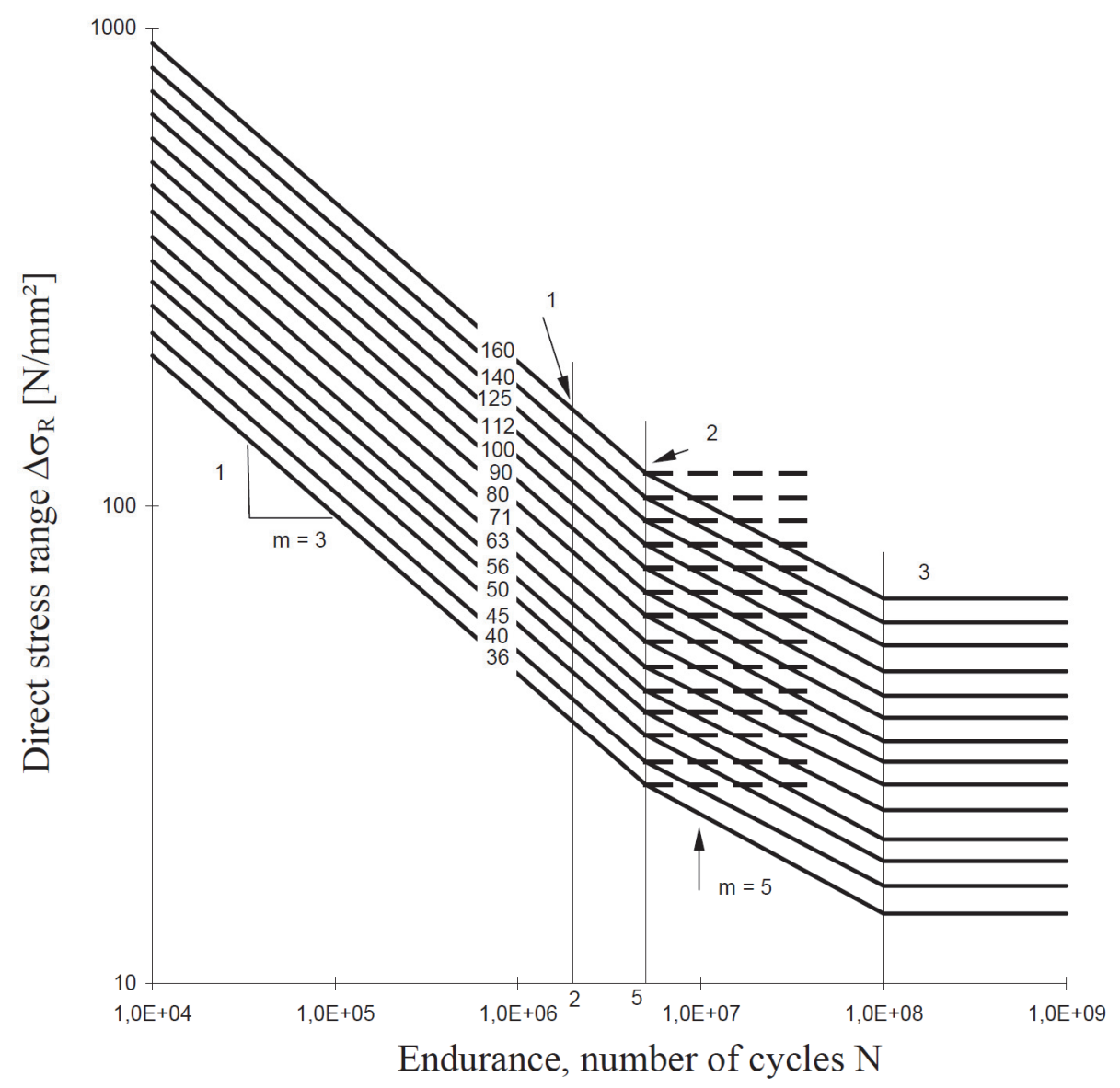

Figure 1: S-N-curves of different FAT classes for fatigue assessment of welded joints, according to the Eurocode 3.

The Eurocode 3 is based mainly on the approach described above, defining a series of S-N-curves to choose by the FAT classes whose value is defined on the base of the shape, the loading conditions and the most relevant geometrical parameters of the detail considered. This method represents, still nowadays, the base for fatigue assessment in almost all areas of mechanical and structural engineering due to its relative simplicity, although this implicates also an excessive conservative design. Even if this is generally accepted because of the difficulties to perform a more precise fatigue assessment, it is undesirable in those mechanical fields that require a lightweight design such as automotive and aircraft engineering.

Most of the standards suggest also the structural stress approach which considers the stress concentration effects of the component due to the global geometry [1,3-4]. The value of the structural stress may be measured by strain gauges on the real component or assessed either analytically by engineering formulae or numerically by Finite Element (FE) analysis. As the nominal stress approach, the structural stress approach allows the fatigue assessment using the structural stresses with an S-N curve but with the advantage that only one FAT-class must be used depending on the type of weld. On the other hand, as discussed in ref. [5], this method has also some drawbacks. Firstly, it is applicable only to components whose failure is due to the weld toe. Secondly, the determination of the structural stress is not so easy even using FE methods because of its dependence on element properties and discretization. Thirdly, different structural stress approaches could be considered leading to quite similar results but to a conservative design in comparison with the results of experimental fatigue tests.

The methods discussed above are widely appreciated because of their simplicity and statistical proof. However, their validation is based on tests carried out on geometry and conditions that are rarely encountered in practical applications 
whose assessment, in this way, lacks actually a statistical validation. In these cases the local approaches, although less suited to standardisation, are able to evaluate with more accuracy the fatigue strength of the detail analysed.

Each of these methods can be distinguished according to the local parameter chosen to determine the fatigue strength [6]. The use of these approaches for welded joints has, of course, some complications due to welding peculiarities, that are in many cases neglected or treated in a statistical way but are also able to match the user need of a more realistic evaluation of the fatigue strength with a relatively simple approach. Although these methods require expertise in their application, they allow evaluating the effect of more parameters on the fatigue strength with a relatively low cost. On the other hand, a practicable application of the local approaches requires the determination of those parameters that have a decisive influence in the fatigue strength in order to avoid complicating, even more, the problem. The detection of these parameters requires sensitivity analysis. Welding height and the lack of penetration were studied in this work with this aim.

\section{STRAIN ENERGY DENSITY METHOD}

7 he local strain energy density (SED) approach [7], as formalized by Lazzarin et al. and named 'finite volume energybased approach' or 'equivalent strain energy density approach' in their first works [8,9], has been validated as a method to investigate both fracture in static condition and fatigue failure.

Brittle fracture at pointed V-notches can be assumed to occur when the local SED W, averaged in a given control volume, reaches a critical value $\bar{W}=W_{C}$ that is independent of the notch opening angle and of the loading type [8]. The mean SED critical value is evaluable, for an ideally brittle material, through the conventional ultimate tensile strength $\sigma_{t}$ :

$$
\mathrm{W}_{\mathrm{C}}=\frac{\sigma_{\mathrm{t}}^{2}}{2 \mathrm{E}}
$$

What stated above represents the basic idea of the SED method. This is reminiscent of Beltrami criterion [10] but also of Neuber's concepts of an elementary material volume [11-13], an idea exploited also in many theories of other researchers [14-16]. With the aim to clarify the background of this criterion, it is worth quoting some fundamental contributions as regards brittle fracture. Dealing with cracked plate under mode I and mode II loading, one of the basic ideas is the mode I dominance concept that was suggested in [17] to investigate fracture and to predict the crack kinking angle. According to this concept, the crack grows in the direction almost perpendicular to the maximum tangential stress in radial direction from its tip. The central idea of the Erdogan-Sih's criterion is fundamental to investigate also the case of blunt notches under mixed mode loading. Another important theory to take into account is the Sih's approach [18] that considers as fundamental parameter the strain energy density factor $\mathrm{S}$, defined as the product of the strain energy density by a critical distance from the point of singularity. According to this method, the fracture is controlled by a critical value of this parameter $S_{C}$ while the direction of crack propagation was determined by imposing a minimum condition on $\mathrm{S}$. This theory encloses also blunt crack and notch tip [19] and components of ductile materials [20]. A local-SED based criterion, that assumes the SED constancy around the notch tip, has been proposed also by Glinka and Molski [21] to consider also the application to sharp $\mathrm{V}$-notches in plain strain condition and small yielding [9]. For more consideration about correspondences and differences characterising various SED-based criteria, we remand at the ref. [22].

We introduce here the analytical frame of the local SED approach. The total strain energy density, under the hypothesis of linear elastic isotropic material, is given by:

$$
W(r, \theta)=\frac{1}{2 E}\left\{\sigma_{11}^{2}+\sigma_{22}^{2}+\sigma_{33}^{2}-2 v\left(\sigma_{11} \sigma_{22}+\sigma_{11} \sigma_{33}+\sigma_{22} \sigma_{33}\right)+2(1+v) \sigma_{12}^{2}\right\}
$$

Dealing with sharp V-notch under the hypothesis of plane stress or plane strain conditions and of linear-elastic isotropic material $[8,9]$, by using the polar coordinate system $(r, \theta)$ shown in Fig. 2, the stress distributions, close to the notch tip, due to mode I loading are [23]:

$$
\left\{\begin{array}{c}
\sigma_{\theta} \\
\sigma_{r} \\
\tau_{r \theta}
\end{array}\right\}_{\rho=0}=\frac{1}{\sqrt{2 \pi}} \frac{r^{\lambda_{1}-1} K_{1}^{N}}{\left(1+\lambda_{1}\right)+\chi_{1}\left(1-\lambda_{1}\right)}\left[\left\{\begin{array}{c}
\left(1+\lambda_{1}\right) \cos \left(1-\lambda_{1}\right) \theta \\
\left(3-\lambda_{1}\right) \cos \left(1-\lambda_{1}\right) \theta \\
\left(1-\lambda_{1}\right) \sin \left(1-\lambda_{1}\right) \theta
\end{array}\right\}+\chi_{1}\left(1-\lambda_{1}\right)\left\{\begin{array}{r}
\cos \left(1+\lambda_{1}\right) \theta \\
-\cos \left(1+\lambda_{1}\right) \theta \\
\sin \left(1+\lambda_{1}\right) \theta
\end{array}\right\}\right]
$$




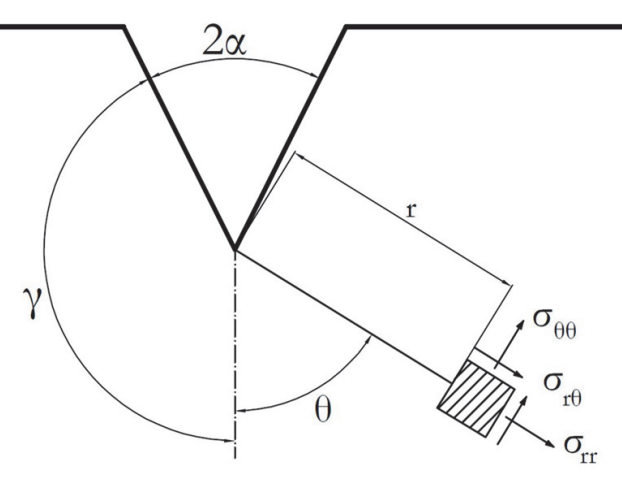

Figure 2: Coordinate system and symbols used for the stress field components.

While the skew-symmetric stress distributions, due to mode II loading, are:

$$
\left\{\begin{array}{c}
\sigma_{\theta} \\
\sigma_{r} \\
\tau_{r \theta}
\end{array}\right\}_{\rho=0}=\frac{1}{\sqrt{2 \pi}} \frac{r^{\lambda_{2}-1} K_{2}^{N}}{\left(1-\lambda_{2}\right)+\chi_{2}\left(1+\lambda_{2}\right)}\left[\left\{\begin{array}{c}
-\left(1+\lambda_{2}\right) \sin \left(1-\lambda_{2}\right) \theta \\
-\left(3-\lambda_{2}\right) \sin \left(1-\lambda_{2}\right) \theta \\
\left(1-\lambda_{2}\right) \cos \left(1-\lambda_{2}\right) \theta
\end{array}\right\}+\chi_{2}\left(1+\lambda_{2}\right)\left\{\begin{array}{c}
-\sin \left(1+\lambda_{2}\right) \theta \\
\sin \left(1+\lambda_{2}\right) \theta \\
\cos \left(1+\lambda_{2}\right) \theta
\end{array}\right\}\right]
$$

$K_{1}$ and $K_{2}$ being the Notch stress intensity factors (NSIFs) related to mode I and mode II stress distributions. The NSIFs can be assessed by [24]:

$$
\begin{aligned}
& K_{1}^{N}=\sqrt{2 \pi} \lim _{r \rightarrow 0^{+}} r^{1-\lambda_{1}} \sigma_{\theta \theta}(r, \theta=0) \\
& K_{2}^{N}=\sqrt{2 \pi} \lim _{r \rightarrow 0^{+}} r^{1-\lambda_{2}} \sigma_{r \theta}(r, \theta=0)
\end{aligned}
$$

Where $\lambda_{1}$ and $\lambda_{2}$ are Williams' eigenvalues [23] and $\chi_{1}$ and $\chi_{2}$ are auxiliary parameters function of opening angle. Tab. 2 gives the parameters for mode I and mode II stress distributions.

Exploiting the superposition effect principle, the stress distributions close to the notch tip in a mixed mode loading (I+II) can be expressed as follows:

$$
\sigma_{i j}(r, \theta)=r^{\lambda_{1}-1} \cdot K_{1} \cdot\left|\begin{array}{ccc}
\tilde{\sigma}_{\theta \theta}^{(1)} & \tilde{\sigma}_{r \theta}^{(1)} & 0 \\
\tilde{\sigma}_{r \theta}^{(1)} & \tilde{\sigma}_{r r}^{(1)} & 0 \\
0 & 0 & \tilde{\sigma}_{\text {r⿱ }}^{(1)}
\end{array}\right|+r^{\lambda_{2}-1} \cdot K_{2}^{N} \cdot\left|\begin{array}{ccc}
\tilde{\sigma}_{\theta \theta}^{(2)} & \tilde{\sigma}_{r \theta}^{(2)} & 0 \\
\tilde{\sigma}_{r \theta}^{(2)} & \tilde{\sigma}_{r r}^{(2)} & 0 \\
0 & 0 & \tilde{\sigma}_{\text {z⿱ }}^{(2)}
\end{array}\right|
$$

Where $\tilde{\sigma}_{\theta \theta}, \tilde{\sigma}_{r r}$ and $\tilde{\sigma}_{r \theta}$ for mode I and mode II can be derived from Eqns. (3), (4) as a function of the notch opening angle $2 \alpha$ and of the position whit the polar coordinate $\theta$.

Eqn. (7) describes the degree of the singularity of the stress fields due to re-entrant corners by mode I and mode II. In the case considered above, as the stresses, also the strain energy density tends towards infinity. On the other hand, the average SED in a local finite volume around the notch tip has a finite value that is considered to control failure. By substituting the expressions for stresses distributions reported in Eqn. (7) into Eqn. (2) it is possible to obtain:

$$
W(r, \theta)=W_{1}(r, \theta)+W_{2}(r, \theta)+W_{12}(r, \theta)
$$

\section{Being:}




$$
\begin{aligned}
& W_{1}(r, \theta)=\frac{1}{2 E} \cdot r^{2\left(\lambda_{1}-1\right)} \cdot\left(K_{1}\right)^{2}\left[\tilde{\sigma}_{\theta \theta}^{(1)^{2}}+\tilde{\sigma}_{r r}^{(1)^{2}}+\tilde{\sigma}_{z^{\prime}}^{(1)^{2}}-2 v\left(\tilde{\sigma}_{\theta \theta}^{(1)} \tilde{\sigma}_{r r}^{(1)}+\tilde{\sigma}_{\theta \theta}^{(1)} \tilde{\sigma}_{z^{\prime}}^{(1)}+\tilde{\sigma}_{z^{\prime}}^{(1)} \tilde{\sigma}_{r r}^{(1)}\right)+2(1+v) \tilde{\sigma}_{r \theta}^{(1)^{2}}\right]
\end{aligned}
$$

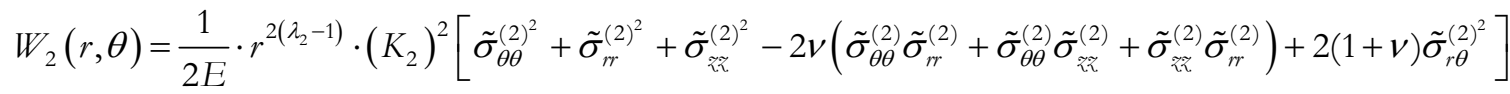

$$
\begin{aligned}
& W_{12}(r, \theta)=\frac{1}{E} \cdot r^{\lambda_{1}+\lambda_{2}-2} \cdot K_{1} \cdot K_{2}\left[\tilde{\sigma}_{\theta \theta}^{(1)} \tilde{\sigma}_{\theta \theta}^{(2)}+\tilde{\sigma}_{r r}^{(1)} \tilde{\sigma}_{r r}^{(2)}+\tilde{\sigma}_{\text {z⿱ }}^{(1)} \tilde{\sigma}_{\text {范 }}^{(2)}+\right.
\end{aligned}
$$

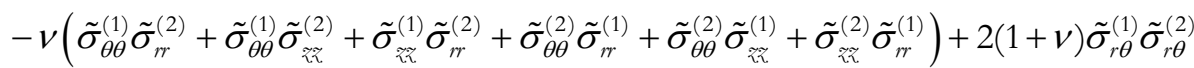

In order to evaluate the averaged value of the strain energy density, a sector-shaped cylinder of radius $R_{0}$ along the notch tip line, called 'control volume', is considered. For more consideration about the shape of the control volume, we remand to ref [25-27]. The control volume radius $R_{0}$ depends only on the material and its value decreases with increasing brittleness. In plane problems, both in mode I and mixed mode (I+II) loading, the control volume becomes a circle or a circular sector with radius $R_{0}$ respectively in the case of cracks and pointed V-notches, as shown in Fig. 3.

a)

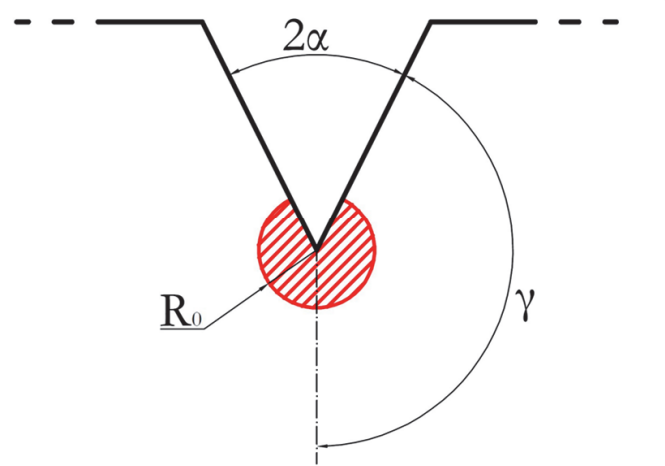

b)

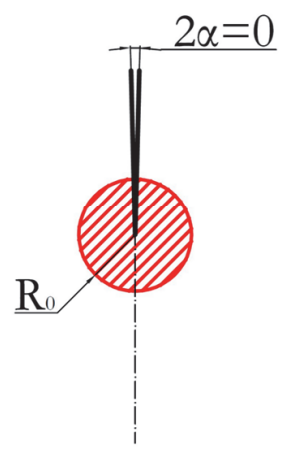

Figure 3: Control volume (area) for: a) sharp V-notch; b) crack.

The radius $R_{0}$ can be estimated for the crack case under plane strain and plane stress conditions as follows [28-30]:

$$
\begin{array}{ll}
\mathrm{R}_{0}=\frac{(1+v)(5-8 v)}{4 \pi}\left(\frac{K_{I C}}{\sigma_{t}}\right)^{2} & \text { plane strain } \\
\mathrm{R}_{0}=\frac{(5-3 v)}{4 \pi}\left(\frac{K_{C}}{\sigma_{t}}\right)^{2} & \text { plane stress }
\end{array}
$$

While in the case of a pointed V-notch the critical radius can be assessed by [8]:

$$
R_{0}=\left[\frac{I_{1} \cdot K_{1 C}^{2}}{4 \lambda_{1}(\pi-\alpha) E W_{C}}\right]^{\frac{1}{2\left(1-\lambda_{1}\right)}}=\left[\frac{I_{1}}{2 \lambda_{1}(\pi-\alpha)}\left(\frac{K_{1 C}}{\sigma_{t}}\right)^{2}\right]^{\frac{1}{2\left(1-\lambda_{1}\right)}}
$$

The values of $\lambda$ and $I_{1}$ depending on $\alpha$ and on the stresses field are reported in Tab. 1. In the case of mode I loading $K_{1 C}$ equals the fracture toughness $K_{I C}$. 


\begin{tabular}{|c|c|c|c|c|c|c|c|c|c|c|}
\hline $2 \alpha\left[^{\circ}\right]$ & $\gamma / \pi[\mathrm{rad}]$ & $\lambda_{1}$ & $v=0.10$ & $v=0.15$ & $v=0.20$ & $\begin{array}{c}I_{1} \text { Pl. Strain } \\
v=0.25\end{array}$ & $v=0.30$ & $v=0.35$ & $v=0.40$ & $\begin{array}{c}I_{1} \text { Pl. Stress } \\
v=0.30\end{array}$ \\
\hline 0 & 1 & 0.5000 & 1.1550 & 1.0925 & 1.0200 & 0.9375 & 0.8450 & 0.7425 & 0.6300 & 1.0250 \\
\hline 15 & $23 / 24$ & 0.5002 & 1.1497 & 1.0880 & 1.0162 & 0.9346 & 0.8431 & 0.7416 & 0.6303 & 1.0216 \\
\hline 30 & $11 / 12$ & 0.5014 & 1.1335 & 1.0738 & 1.0044 & 0.9254 & 0.8366 & 0.7382 & 0.6301 & 1.0108 \\
\hline 45 & $7 / 8$ & 0.5050 & 1.1063 & 1.0499 & 0.9841 & 0.9090 & 0.8247 & 0.7311 & 0.6282 & 0.9918 \\
\hline 60 & $5 / 6$ & 0.5122 & 1.0678 & 1.0156 & 0.9547 & 0.8850 & 0.8066 & 0.7194 & 0.6235 & 0.9642 \\
\hline 90 & $3 / 4$ & 0.5445 & 0.9582 & 0.9173 & 0.8690 & 0.8134 & 0.7504 & 0.6801 & 0.6024 & 0.8826 \\
\hline 120 & $2 / 3$ & 0.6157 & 0.8137 & 0.7859 & 0.7524 & 0.7134 & 0.6687 & 0.6184 & 0.5624 & 0.7701 \\
\hline 135 & $5 / 8$ & 0.6736 & 0.7343 & 0.7129 & 0.6867 & 0.6558 & 0.6201 & 0.5796 & 0.5344 & 0.7058 \\
\hline 150 & $7 / 12$ & 0.7520 & 0.6536 & 0.6380 & 0.6186 & 0.5952 & 0.5678 & 0.5366 & 0.5013 & 0.6386 \\
\hline
\end{tabular}

Table 1: Parameters $I_{1}$ for pointed V-notches under plane stress and plane strain conditions.

The elastic deformation energy in the control volume around the notch tip is given as follows:

$$
E_{(R)}=\int_{A} W \cdot d A=\int_{0}^{R} \int_{-\gamma}^{+\gamma}\left[W_{1}(r, \theta)+W_{2}(r, \theta)+W_{12}(r, \theta)\right] \cdot r d r d \theta
$$

The integration field is symmetric with respect to the notch bisector; this condition sets to zero the contribution of $W_{12}$. Therefore:

$$
E_{(R)}=E_{1(R)}+E_{2(R)}=\frac{1}{E} \cdot \frac{I_{1(\gamma)}}{4 \lambda_{1}} \cdot\left(K_{1}\right)^{2} \cdot R^{2 \lambda_{1}}+\frac{1}{E} \cdot \frac{I_{2(\gamma)}}{4 \lambda_{2}} \cdot\left(K_{2}\right)^{2} \cdot R^{2 \lambda_{2}}
$$

Where $I_{1(\gamma)}$ and $I_{2(\gamma)}$ are:

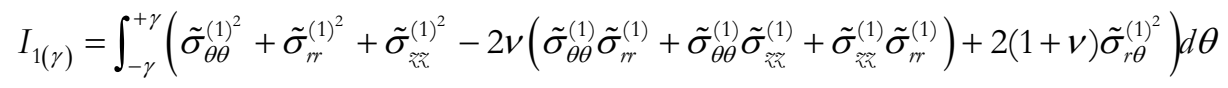

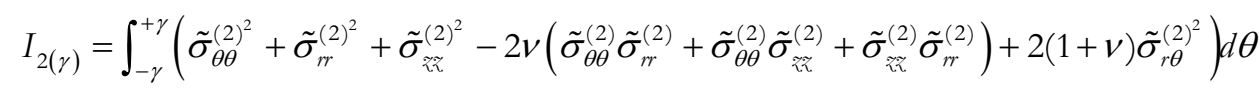

Their values, assessed for different geometries and stresses field, are reported in Tab. 1 as a function of Poisson's ratio. The value of the area on which the integration is carried out is given by:

$$
A_{(R)}=\int_{0}^{R_{0}} \int_{-\gamma}^{+\gamma} r d r d \theta=R_{0}^{2} \gamma
$$

$\gamma$ being expressed in radians.

The averaged elastic deformation energy on the area results to be:

$$
\bar{W}=\frac{E_{(R)}}{A_{(R)}}=\frac{1}{E} \cdot e_{1} \cdot\left(K_{1}\right)^{2} \cdot R_{0}^{2\left(\lambda_{1}-1\right)}+\frac{1}{E} \cdot e_{2} \cdot\left(K_{2}\right)^{2} \cdot R_{0}^{2\left(\lambda_{2}-1\right)}
$$

Being:

$$
e_{1(2 \alpha)}=\frac{I_{1(\gamma)}}{4 \lambda_{1} \gamma}
$$




$$
e_{2(2 \alpha)}=\frac{I_{2(\gamma)}}{4 \lambda_{2} \gamma}
$$

Taking into account all the three modes of loading, I+II+III, [31] the value of the strain energy density is given by:

$$
\bar{W}=\frac{e_{1}}{E}\left[\frac{K_{1}}{R_{0}^{1-\lambda_{1}}}\right]^{2}+\frac{e_{2}}{E}\left[\frac{K_{2}}{R_{0}^{1-\lambda_{2}}}\right]^{2}+\frac{e_{3}}{E}\left[\frac{K_{1}}{R_{0}^{1-\lambda_{3}}}\right]^{2}
$$

Values of $e_{1}, e_{2}$ and $e_{3}$ are listed in Tab. 2 as a function of the notch opening angle $2 \alpha$.

\begin{tabular}{cccccccccc}
\hline $2 \alpha\left[^{\circ}\right]$ & $\gamma / \pi[\mathrm{rad}]$ & $\lambda_{1}$ & $\lambda_{2}$ & $\lambda_{3}$ & $\chi_{1}$ & $\chi_{2}$ & $e_{1}$ & $e_{2}$ & $e_{3}$ \\
0 & 1 & 0.5000 & 0.5000 & 0.5000 & 1.000 & 1.000 & 0.13449 & 0.34139 & 0.41380 \\
15 & $11 / 12$ & 0.5014 & 0.5982 & 0.5455 & 1.071 & 0.921 & 0.14485 & 0.27297 & 0.37929 \\
30 & $5 / 6$ & 0.5122 & 0.7309 & 0.6000 & 1.166 & 0.814 & 0.15038 & 0.21530 & 0.34484 \\
90 & $3 / 4$ & 0.5445 & 0.9085 & 0.6667 & 1.312 & 0.658 & 0.14623 & 0.16793 & 0.31034 \\
120 & $2 / 3$ & 0.6157 & 1.1489 & 0.7500 & 1.841 & 0.219 & 0.12964 & 0.12922 & 0.27587 \\
135 & $5 / 8$ & 0.6736 & 1.3021 & 0.8000 & 4.153 & -0.569 & 0.11721 & 0.11250 & 0.25863 \\
\hline
\end{tabular}

Table 2: Values of the parameters in Eqn. (23) for a Poisson's ratio $v=0.3$ and under Beltrami hypothesis.

It is worth mentioning that, through Eqn. (23), the SED method allows to evaluate at posteriori the NSIFs [32] that, however, have two major drawbacks: they require an accurate evaluation of the stresses [8] and thus an extremely fine discretization; their critical value is not a constant, but a function of the notch opening angle [23]. The SED method shows another advantage over the NSIFs since its dimensions are constant and its critical value does not depend on the notch opening angle.

The local SED concept has been extended from pointed to blunt V-and U-notches through a semi-empirical procedure validated through numerical simulations [28, 33].

Dealing with blunt notches, it is important to do some considerations about the control volume that, under mode I loading, assumes a crescent shape, with $R_{0}$ being its maximum width along the notch bisector line [28, 29], differently from pointed $\mathrm{V}$ notches. In this case, the control volume is given by the intersection between the component and a circle of radius $r+R_{0}$ centred on the notch bisector, between the notch edge and the notch-fitting radius centre, at a distance $r$ from the notch edge.

Under mixed-mode loading, the maximum elastic stress is out of the notch bisector line and its position along the notch edge is a function of mode I and mode II stress distributions. In this case, the control volume is no longer centred with respect to the notch bisector, but rigidly rotated with respect to it and centred on the point where the SED reaches its maximum value [34-39], following, essentially, the mode I dominance concept.

As regards fracture in static condition, in literature it is possible to find many works carried out in order to validate this method both for pointed $[8,30]$ and blunt [28] V-notched specimens of brittle material.

Regarding the torsional loading (mode III), the material behaviour is completely different with respect to the other loading modes. Experimental tests carried out on notched PMMA specimens [40,41] showed a considerable plastic behaviour and a major influence of the effective resistant net area. This led to the development of a non-conventional approach that considers the 'apparent' linear elastic SED overcoming in this way the problem of different fracture mechanisms that occur under mode III loading.

The use of the SED approach leads to some important advantages [32] that were exploited in the work presented in this paper. It is worth mentioning the SED low sensibility to the mesh refinement [42] being the SED a function of the stiffness matrix and of the nodal displacement. This allows using a coarse discretisation instead of other methods for the fatigue assessment that exploit the stress field like the Notch Stress Intensity Factor that however is strictly connected to the SED method $[43,44]$ through some closed-form relationships (see Eqn. (23)). Another important advantage is the possibility to include three-dimensional effects and out of plane singularities that are not evaluable by William's theory. Besides, as stated above, the SED approach overcomes the complex problem tied to the different NSIF units of measure in the case of different notch opening angles. 
a)
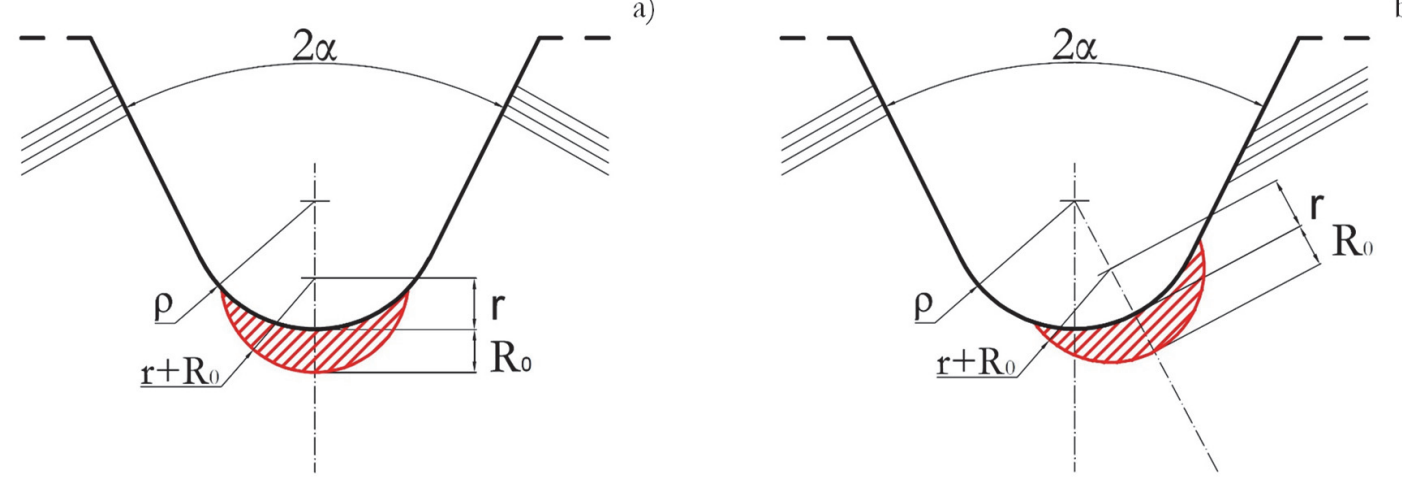

b)

c)
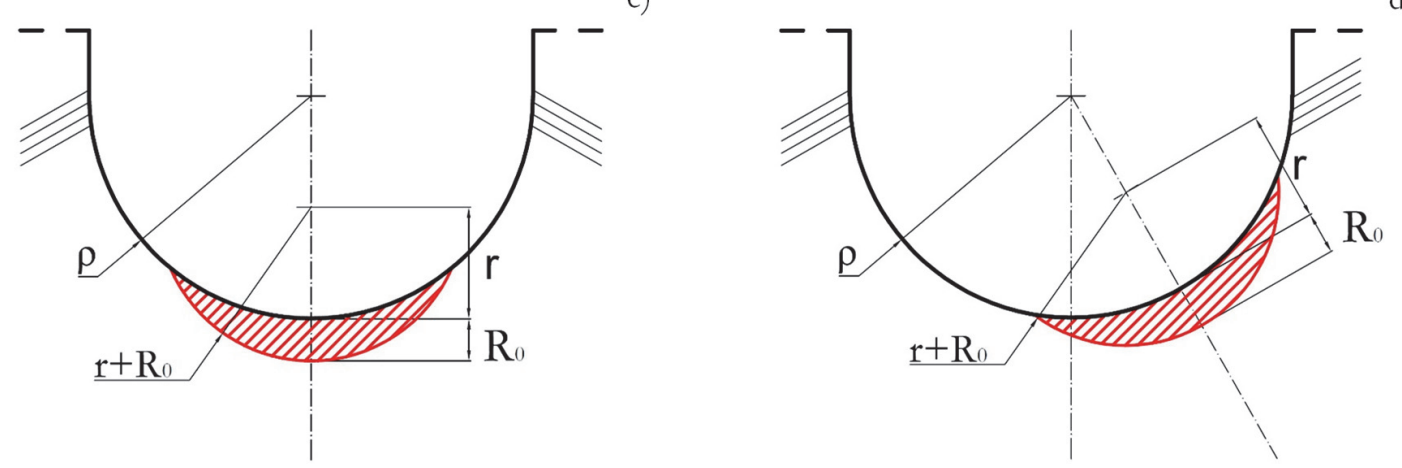

d)

Figure 4: Control volume for: a) blunt V-notch under mode I loading $(r=\rho \cdot(\pi-2 \alpha) /(2 \pi-2 \alpha))$; b) blunt V-notch under mixed mode loading $(r=\rho \cdot(\pi-2 \alpha) /(2 \pi-2 \alpha))$; c) U-notch under mode I loading $(r=\rho / 2)$; d) U-notch under mixed mode loading ( $r=\rho / 2)$.

The high-cycle fatigue failure usually happens in the linear elastic regime and shows a brittle nature. These two conditions allow the use of the SED method, in terms of the cyclic average SED $\Delta \bar{W}$ of the pointed weld notch, dealing with welded joints made of steel or aluminium alloy under different loading conditions [45-48].

According to above, considering a V-notch angle at the weld toe constant and large enough $\left(2 \alpha \geq 102,6^{\circ}\right)$ to ensure the non-singularity of mode II, the radius of the control volume $R_{0}$ can be estimated by means of the expression [8]:

$$
\mathrm{R}_{0}=\left(\frac{\sqrt{2 e_{1}} \Delta K_{1 A}^{N}}{\Delta \sigma_{A}}\right)^{\frac{1}{1-\lambda_{i}}}
$$

Using the material properties of the butt ground welded joint and the N-SIF-based fatigue strength of welded joints $\Delta K_{1 A}^{N}$. Considering a simplified model of the weld toe regions as sharp V-notch, the first theoretical scatter band in terms of cyclic averaged SED $[45,46]$ has been obtained analysing more than 300 fatigue strength data of welded joints characterised by weld toe failure, under different loading conditions. The geometry varied in a great range of the main plane thickness, the transverse plate and the bead flank (but large enough to ensure the non-singularity of mode II). The analysis was later applied in $[45,46]$ to a larger bulk of experimental data, whit fatigue failures both from the weld toe and root, providing a final synthesis based on 900 experimental data, shown in Fig. 5 where the number of cycles to failure is given as a function of $\Delta \bar{W}$. This provides a robust statistical validation for the SED method applied to high-cycle fatigue failure when the welded plate thickness is equal to or greater than $6 \mathrm{~mm}$. 


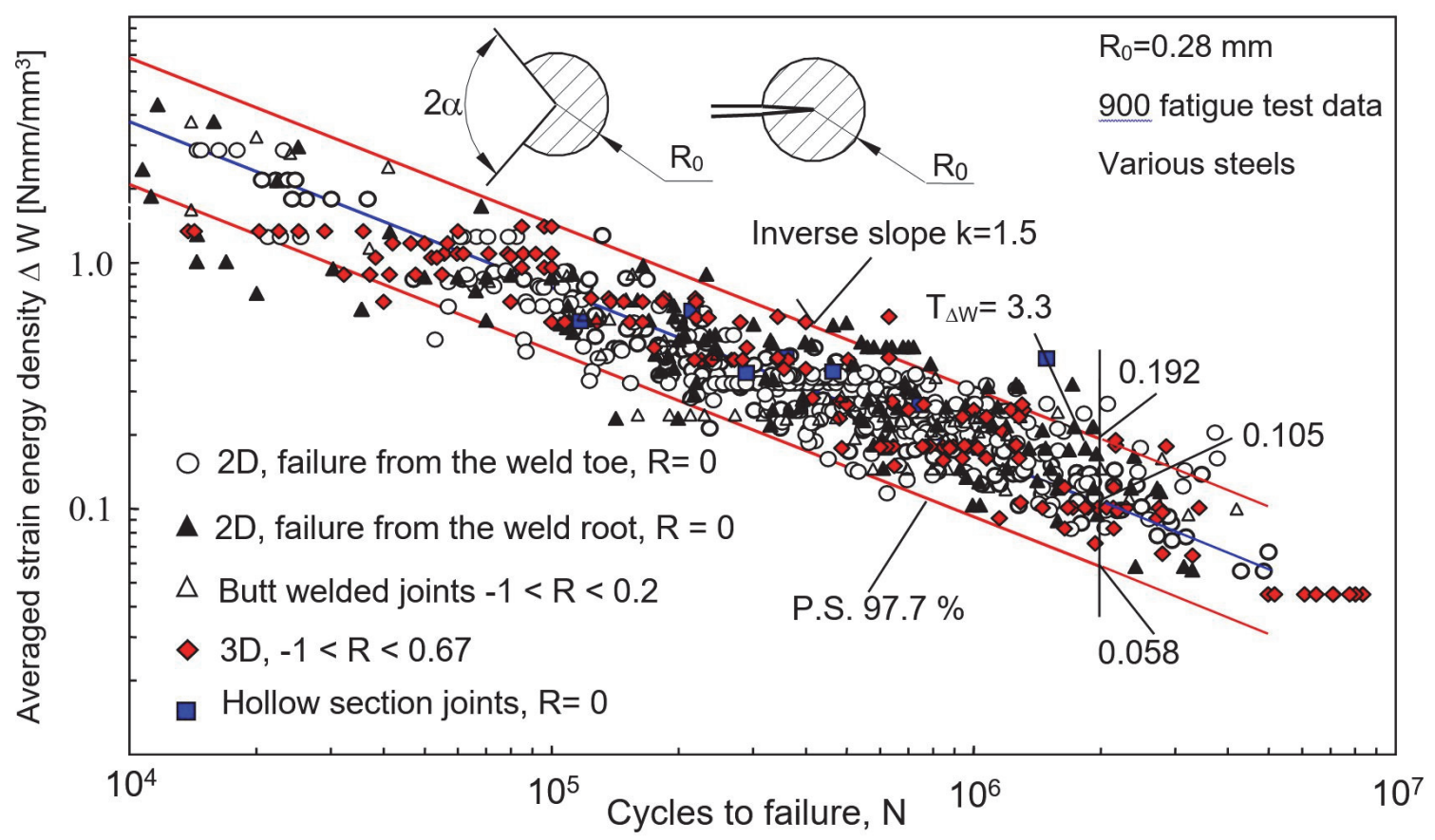

Figure 5: Fatigue strength of steel welded joints as a function of the averaged local strain energy density.

To evaluate the fatigue strength through the SED method, it is enough to calculate the mean-SED at the weld toe or root for a remote tensile load $\Delta \sigma_{1}$ through a static FE simulation. By means of Eqn. (25), valid only under the hypothesis of linear elastic behaviour, it is possible to evaluate the remote tensile load $\Delta \sigma_{L}$ that represents the fatigue limit of the component:

$$
\Delta \sigma_{L}=\Delta \sigma_{i}\left(\frac{\Delta W_{L}}{\Delta W_{i}}\right)^{\frac{1}{2}}
$$

Being $\Delta W_{L}$ the critical value of the mean SED that corresponds to the fatigue limit. As regard steel welded joints, according to above, this value is $0.058 \mathrm{Nmm} / \mathrm{mm}^{3}$ with a probability of survival of $P_{S}=97.7 \%$.

\section{FE MODELLING}

I $\mathrm{n}$ order to perform easily the wide amount of simulations that were needed, a parametric 3-D model of each detail was built. To obtain more efficient analyses and minimise the computational time, the symmetries of the details considered were exploited, using the appropriate symmetry conditions in the FE modelling; thus, only a quarter of the geometry was modelled. A simplified shape was considered for the joint. This was modelled as a sharp, zero radius, V-shaped notch with an opening angle equal to $135^{\circ}$ and considered as an ideal linear elastic continuum. The geometries of the welded joints analysed are shown in Fig 6 while their geometrical parameters values for the reference cases $(k=1)$ are reported in Tab. 3. To evaluate the critical point of the joint, the mean SED curve was acquired along the weld toe. The critical point represents the maximum of this curve. According to the SED approach, to evaluate the mean SED value, a control volume was built along the welding bead centred in the weld toe with a radius of $R_{0}=0.28 \mathrm{~mm}$ determined through Eqn. (24) by using data taken from the literature [49]. 

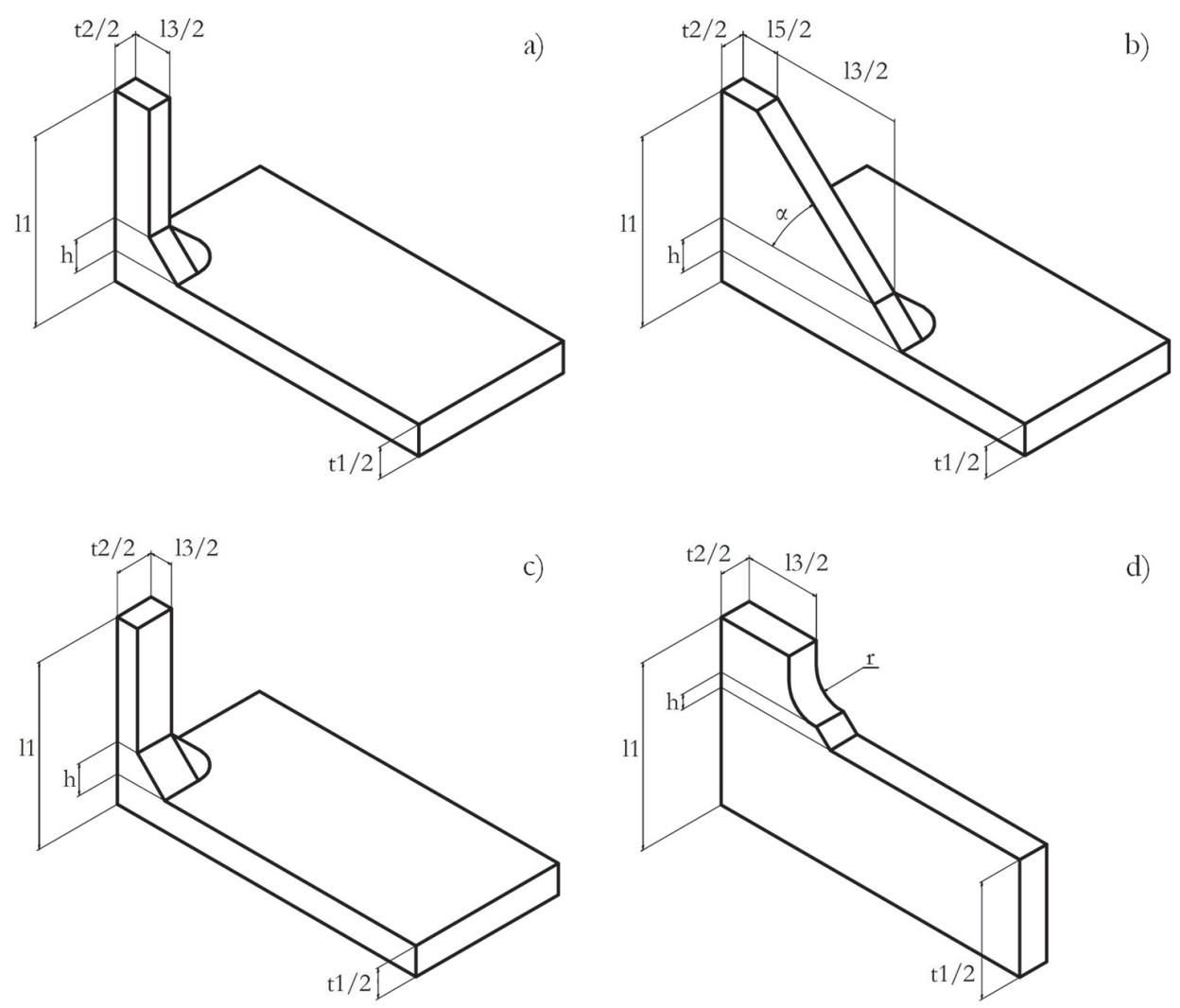

d)

Figure 6: Quarter of geometry of the details analysed: a) longitudinal joint; b) oblique longitudinal joint; c) transverse joint; d) gusset plate welded on the edge of a plate.

\begin{tabular}{ccccccc}
\hline Detail & $\begin{array}{c}11 \\
{[\mathrm{~mm}]}\end{array}$ & $\begin{array}{c}13 \\
{[\mathrm{~mm}]}\end{array}$ & $\begin{array}{c}15 \\
{[\mathrm{~mm}]}\end{array}$ & $\begin{array}{c}\mathrm{t} 1 \\
{[\mathrm{~mm}]}\end{array}$ & $\begin{array}{c}\mathrm{t} 2 \\
{[\mathrm{~mm}]}\end{array}$ & $\begin{array}{c}\text { Alfa } \\
{\left[{ }^{\circ}\right]}\end{array}$ \\
Longitudinal attachment & 48 & 12 & - & 6 & 6 & - \\
Oblique longitudinal attachment & 48 & 12 & 13.2 & 6 & 6 & 44 \\
Transverse attachment & 48 & 12 & - & 6 & 6 & - \\
Gusset plate & 60 & 30 & - & 36 & 6 & - \\
\hline
\end{tabular}

Table 3: Main geometrical parameters of the details analysed for the reference case $(k=1)$.

a)

b)
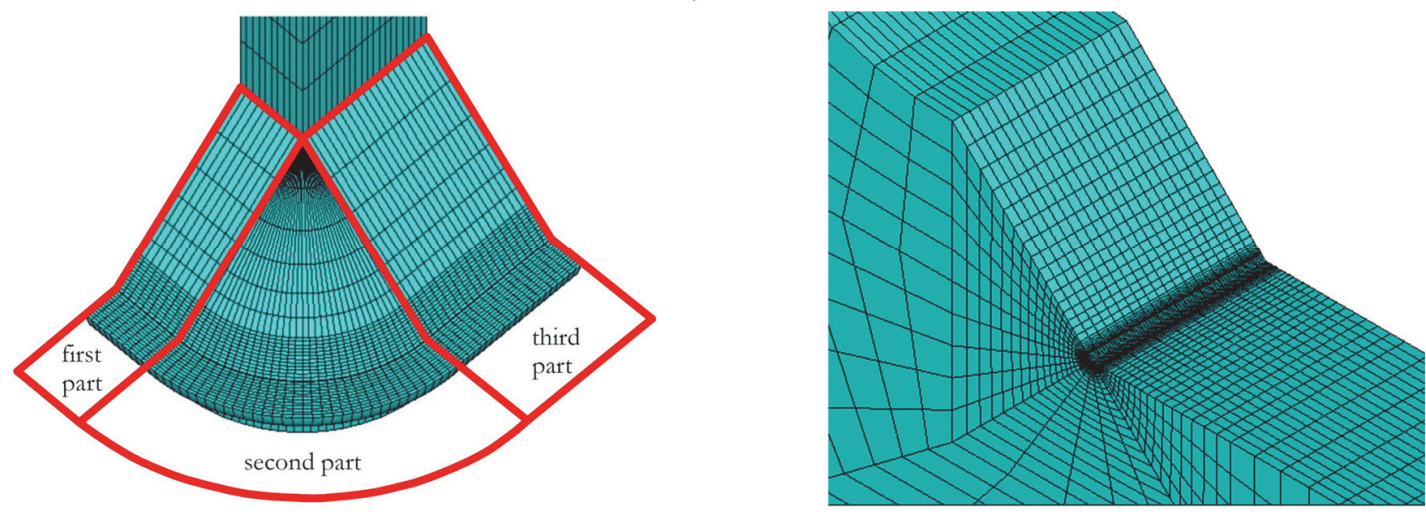

Figure 7: Mesh of the welded joints for: a) longitudinal and transverse joints; b) gusset plate joint. 


\section{SCALE EFFECT FOR WELD ATTACHMENTS AND STIFFENERS}

everal numerical simulations were performed to evaluate the scale effect on the weld attachments and stiffeners

$\mathrm{S}$ subjected to a remote tensile load condition as stated by the design guidance EN 1993-1-9:2005. For each detail, the model was scaled in geometrical proportion with a scale factor $\mathrm{k}$, as shown in Fig. 8, taking as reference the values reported in Tab. 3.

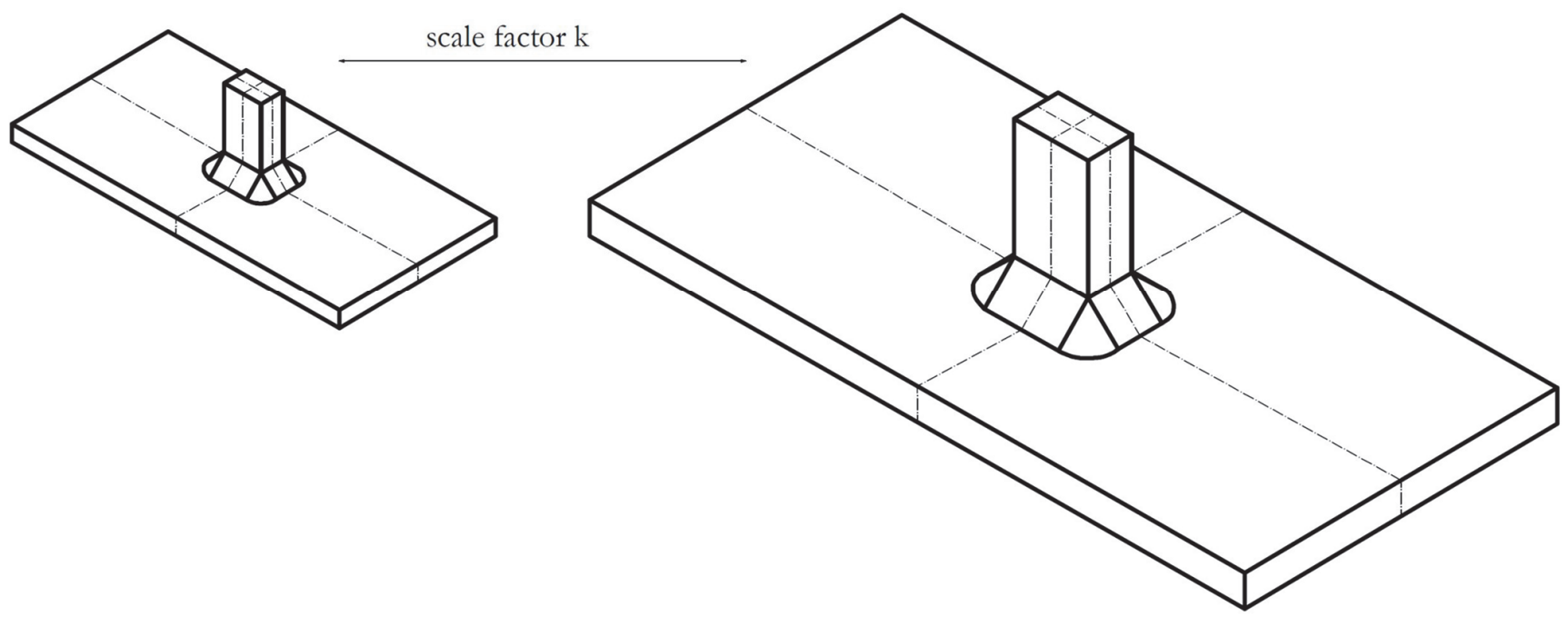

Figure 8: Longitudinal welded joint scaled in geometrical proportion (scale factor k).

The size effect can be explained analytically through the SED theory. Considering two different joints "a" and "b" that have dimensions between them proportional, the NSIFs of the two joints are correlated by:

$$
K_{i, a}=K_{i, b}\left(\frac{t_{a}}{t_{b}}\right)^{1-\lambda_{i}}
$$

By using Eqn. (23) and considering only the mode I loading, the following equation provides a correlation between the mean SED for two details scaled in geometrical proportion:

$$
\Delta \bar{W}_{a}=\Delta \bar{W}_{b}\left(\frac{t_{a}}{t_{b}}\right)^{2\left(1-\lambda_{i}\right)}
$$

It is possible to write the Eqn. (27) also in terms of the fatigue limit as:

$$
\Delta \sigma_{L, a}=\Delta \sigma_{L, b}\left(\frac{t_{a}}{t_{b}}\right)^{1-\lambda_{i}}
$$

As stated above, a simplified model of the joint was considered in this work; thus, considering $\lambda_{1}=0,6736$ according to William's theory, Eqn. (28) was used to calculate the fatigue class of the joints starting from the value found for the reference models through Eqn. (25). The FAT class of the joints was calculated for each model through Eqn. (25) using the mean SED value acquired in the numerical simulations.

The results show a good agreement between the analytical and numerical results for longitudinal and transverse joints as it is possible to see from the last column of Tabs. 6, 7 and 8 that summarise the results of the scale effect for these details. By 
interpolating the numerical results with a power law, it was also possible to evaluate William's eigenvalue $\lambda_{1}$ for longitudinal and transverse attachments. Tab. 4 reports the results of the interpolation. A good agreement was found with William's eigenvalue for each ratio between welding height and main plate thickness.

\begin{tabular}{cccc}
\hline $\mathrm{h} / \mathrm{t} 1$ & Longitudinal joint & $\begin{array}{c}\text { Oblique longitudinal } \\
\text { joint }\end{array}$ & Transverse joint \\
0.5 & 0.680 & 0.677 & 0.684 \\
0.7 & 0.672 & 0.673 & 0.674 \\
1 & 0.664 & 0.665 & 0.664 \\
\hline
\end{tabular}

Table 4: William's eigenvalue for Mode I assessed from numerical simulations.

Regarding the gusset plate, the interpolation of the experimental FAT class data, assessed by Eqn. (25), reveals that an exponent of -0.267 (assessed as the mean value of the data reported in Tab. 5) would be recommended to consider the scale effect for this detail.

\begin{tabular}{ccccc}
\hline \multicolumn{4}{c}{ Gusset plate welded on the edge of a plate } \\
$\mathrm{r} / 1$ & $\mathrm{~h} / \mathrm{t}=0.2$ & $\mathrm{~h} / \mathrm{t}=0.4$ & $\mathrm{~h} / \mathrm{t}=0.7$ & $\mathrm{~h} / \mathrm{t}=1$ \\
$1 / 6$ & -0.267 & -0.275 & -0.266 & -0.262 \\
$1 / 4$ & -0.267 & -0.275 & -0.266 & -0.262 \\
$1 / 3$ & -0.267 & -0.275 & -0.266 & -0.262 \\
\hline
\end{tabular}

Table 5: Exponent of Eqn. 7 assessed by numerical simulation for the gusset plate.

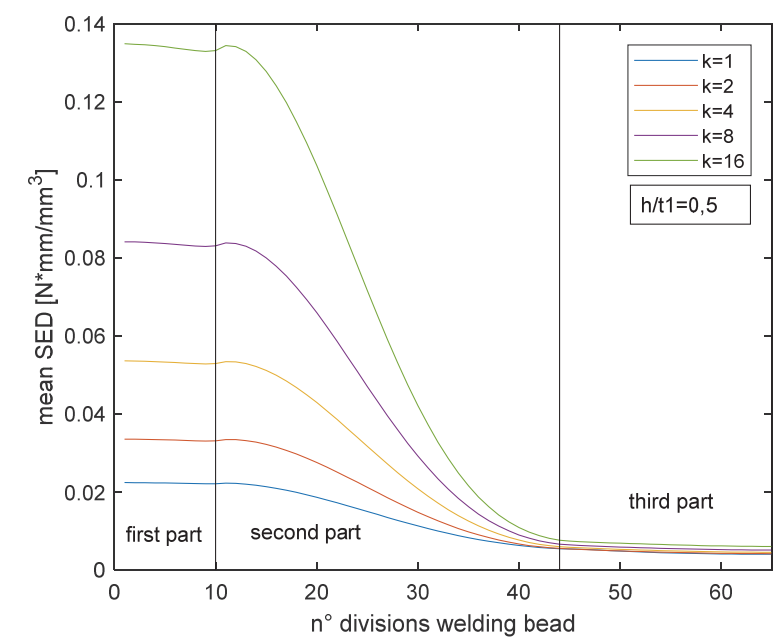

Figure 9: Curves of mean SED along the welding bead for the longitudinal joint.

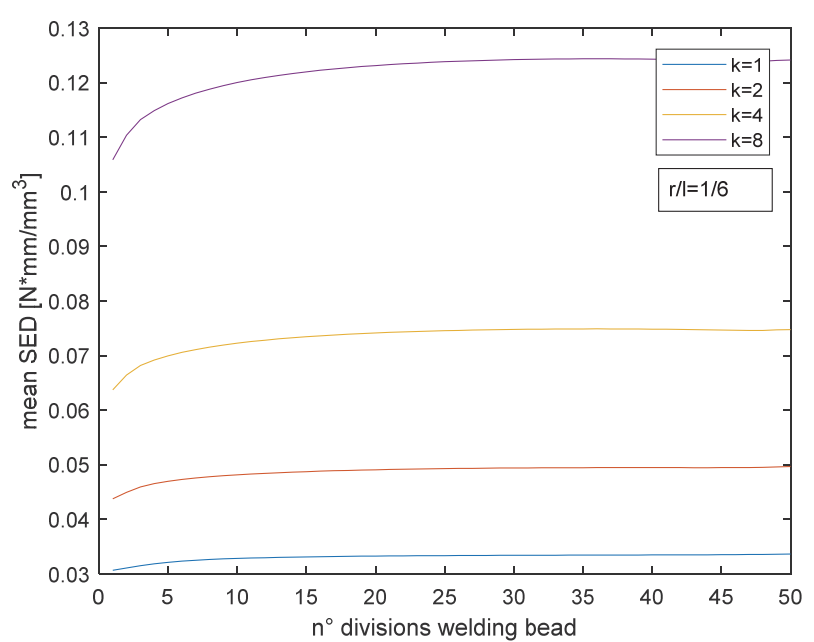

Figure 10: Curves of mean SED along the welding bead for different scales of the gusset plate welded on a plate.

For the longitudinal joint and for the gusset plate the mean SED curves along the weld bead are reported in Figs. 9 and 10 for each scale of the model. Since the transverse joints and the oblique longitudinal joints have curves qualitatively similar to the longitudinal joint we avoid reporting them. 
As it is possible to see from the curves in Figs. 9 and 10, the mean SED present a maximum along the welded bead. This value was used in all the considerations about both the scale effect and the effect of the welding height and weld penetration treated in the next section. Regarding longitudinal and transverse joints, the critical point, identified for each simulation, is always in the second part of the welding joint according to Fig. 7, except for the longitudinal joints characterised by a ratio $b / t 1$ equal to 0.5 . In these last cases, the critical point of the joints is in the first part of the welding joint at the midplane. As regards the gusset plate, the critical point is always located at the midplane of the detail.

\section{EFFECT OF WELDING HEIGHT AND WELD PENETRATION}

F or the details analysed, the effect of the welding height was also evaluated for each model of the details. The design guidance EN 1993-1-9:2005 does not consider the effect of this parameter on the fatigue strength of the component even if its effect has been analysed by Atzori et al. [50] and by Balasubramanian et al. [51] for cruciform joints revealing possible beneficial effects on the fatigue class of the component. Considering the longitudinal and transverse joints, to investigate the effect of this parameter, three different conditions for each scale of the models were considered referring the welding height to the thickness of the base plate while for the gusset plate four different conditions were taken into account. For each model, the reference case corresponds to a ratio between welding height and base plate thickness equals to 0.5 and to 0.2 respectively for longitudinal and transverse joints and for the gusset plate.

As regards longitudinal and transverse joints, the results, summarised in Tabs. 6, 7 and 8, reveal that the assessed FAT class increases with increasing welding height. However, the relative deviation $\% \Delta$ is always lower than $3.5 \%$.

Instead, considering the gusset plate, the fatigue strength decreases with increasing welding height. The relative deviation $\% \Delta$ for the cases analysed can reach also a value of $-15 \%$. Analysing the results for this detail it was found that for a ratio $b / t<0.4$ the fatigue strength of the detail is no more influenced by the welding height. The increase in fatigue strength that is possible to evaluate from the results has to be referred only to the different values of the fitting radius.

For the longitudinal joints, the mean SED curves along the weld bead are reported in Fig. 11 for each welding height, considering only the models characterised by $\mathrm{k}=1$. Since the other cases considered in this work are qualitatively similar, we avoid reporting them.

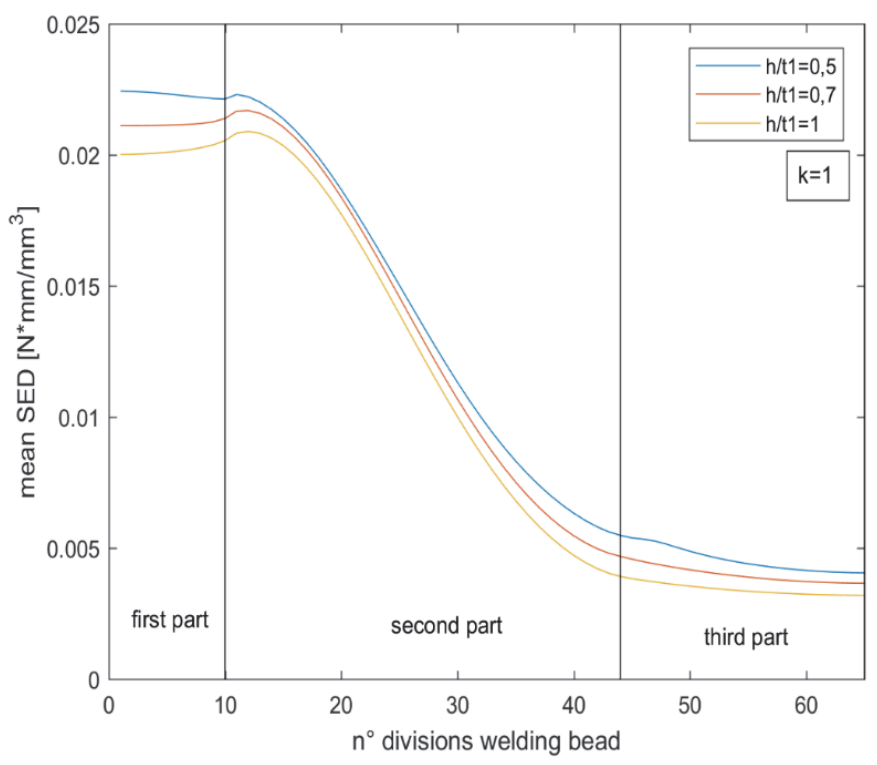

Figure 11: Curves of the mean SED along the welding bead for the longitudinal joint.

The effect of weld penetration on the fatigue strength was also analysed for longitudinal and transverse attachments. Even if an effective benefit was found, it is always lower than $1 \%$ referring to the equivalent case with lack of penetration. Besides, the numerical simulations reveal that this benefit on fatigue strength increases with decreasing welding height. The numerical results are reported in Tabs. 6,7 and 8. 
P. Foti et alii, Frattura ed Integrità Strutturale, 47 (2019) 104-125; DOI: 10.3221/IGF-ESIS.47.09

\begin{tabular}{|c|c|c|c|c|c|c|}
\hline \multirow{3}{*}{$\begin{array}{c}\text { Scale } \\
\mathrm{k}\end{array}$} & \multirow{3}{*}{$\mathrm{h} / \mathrm{t} 1$} & \multicolumn{3}{|c|}{ Numerical } & \multicolumn{2}{|c|}{ Analytical } \\
\hline & & $\begin{array}{c}\text { SED } \\
{\left[\mathrm{Nmm} / \mathrm{mm}^{3}\right]}\end{array}$ & $\begin{array}{c}\text { FAT CLASS } \\
{[\mathrm{MPa}]}\end{array}$ & $\% \Delta$ & $\begin{array}{c}\text { FAT CLASS } \\
{[\mathrm{MPa}]}\end{array}$ & $\% \Delta$ \\
\hline & & & Eqn. (25) & i & Eqn. $(28)^{\mathrm{ii}}$ & iii \\
\hline \multicolumn{7}{|c|}{ With lack of penetration } \\
\hline \multirow{3}{*}{1} & 0.5 & 0.0224 & 90.05 & - & 92.80 & 3.05 \\
\hline & 0.7 & 0.0217 & 91.57 & 1.69 & 93.10 & 1.67 \\
\hline & 1 & 0.0209 & 93.30 & 3.61 & 94.38 & 1.16 \\
\hline \multirow{3}{*}{2} & 0.5 & 0.0336 & 73.61 & - & 74.01 & 0.54 \\
\hline & 0.7 & 0.0333 & 73.87 & 0.35 & 74.25 & 0.51 \\
\hline & 1 & 0.0321 & 75.25 & 2.23 & 74.27 & 1.30 \\
\hline \multirow{3}{*}{4} & 0.5 & 0.0536 & 58.24 & - & 58.24 & - \\
\hline & 0.7 & 0.0533 & 58.43 & 0.33 & 58.43 & - \\
\hline & 1 & 0.0518 & 59.23 & 1.70 & 59.23 & - \\
\hline \multirow{3}{*}{8} & 0.5 & 0.0842 & 46.49 & - & 46.45 & 0.09 \\
\hline & 0.7 & 0.0841 & 46.51 & 0.04 & 46.60 & 0.19 \\
\hline & 1 & 0.0823 & 47.01 & 1.12 & 47.24 & 0.49 \\
\hline \multirow{4}{*}{16} & 0.5 & 0.1349 & 36.71 & - & 37.05 & 0.93 \\
\hline & 0.7 & 0.1378 & 36.33 & 1.04 & 37.17 & 2.31 \\
\hline & 1 & 0.1402 & 36.02 & 1.88 & 37.68 & 4.61 \\
\hline & \multicolumn{4}{|c|}{ With complete penetration } & & \\
\hline \multirow{3}{*}{1} & 0.5 & 0.0220 & 90.86 & 0.90 & 93.61 & 3.03 \\
\hline & 0.7 & 0.0216 & 91.77 & 0.22 & 93.33 & 1.70 \\
\hline & 1 & 0.0209 & 93.34 & 0.04 & 94.42 & 1.16 \\
\hline \multirow{3}{*}{2} & 0.5 & 0.0330 & 74.21 & 0.82 & 74.65 & 0.59 \\
\hline & 0.7 & 0.0332 & 74.05 & 0.24 & 74.43 & 0.51 \\
\hline & 1 & 0.0321 & 75.28 & 0.04 & 75.30 & 0.03 \\
\hline \multirow{3}{*}{4} & 0.5 & 0.0527 & 58.75 & 0.88 & 58.75 & - \\
\hline & 0.7 & 0.0530 & 58.58 & 0.26 & 58.58 & - \\
\hline & 1 & 0.0518 & 59.26 & 0.05 & 59.26 & - \\
\hline \multirow{3}{*}{8} & 0.5 & 0.0827 & 46.90 & 0.88 & 46.85 & -0.11 \\
\hline & 0.7 & 0.0837 & 46.63 & 0.26 & 46.72 & 0.19 \\
\hline & 1 & 0.0822 & 47.03 & 0.04 & 47.26 & 0.49 \\
\hline \multirow{3}{*}{16} & 0.5 & 0.1326 & 37.04 & 0.90 & 37.37 & 0.89 \\
\hline & 0.7 & 0.1371 & 36.42 & 0.25 & 37.26 & 2.31 \\
\hline & 1 & 0.1400 & 36.04 & 0.06 & 37.69 & 4.58 \\
\hline
\end{tabular}

Table 6: Scale effect for longitudinal attachment. 


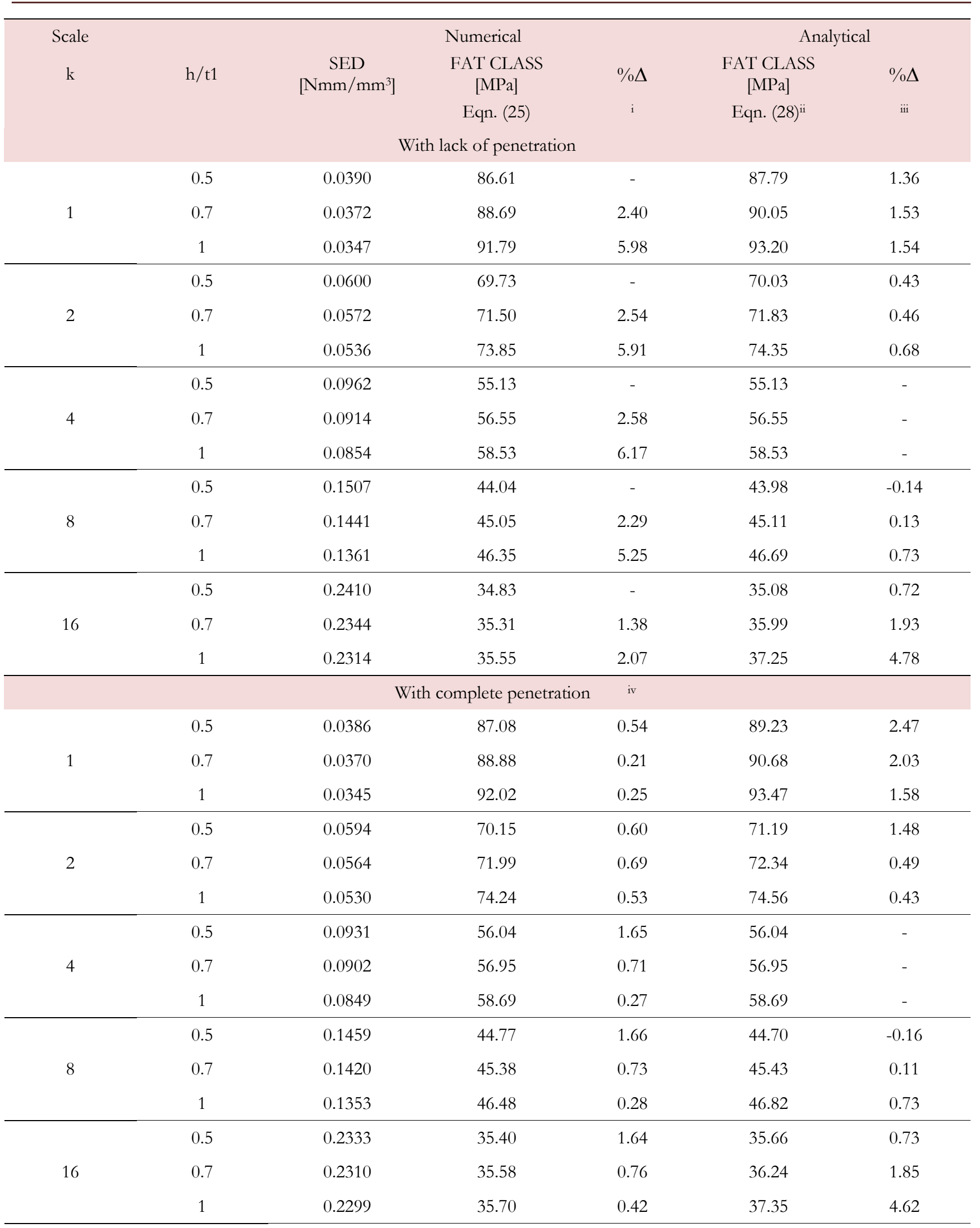

Table 7: Scale effect for oblique longitudinal attachment. 
P. Foti et alii, Frattura ed Integrità Strutturale, 47 (2019) 104-125; DOI: 10.3221/IGF-ESIS.47.09

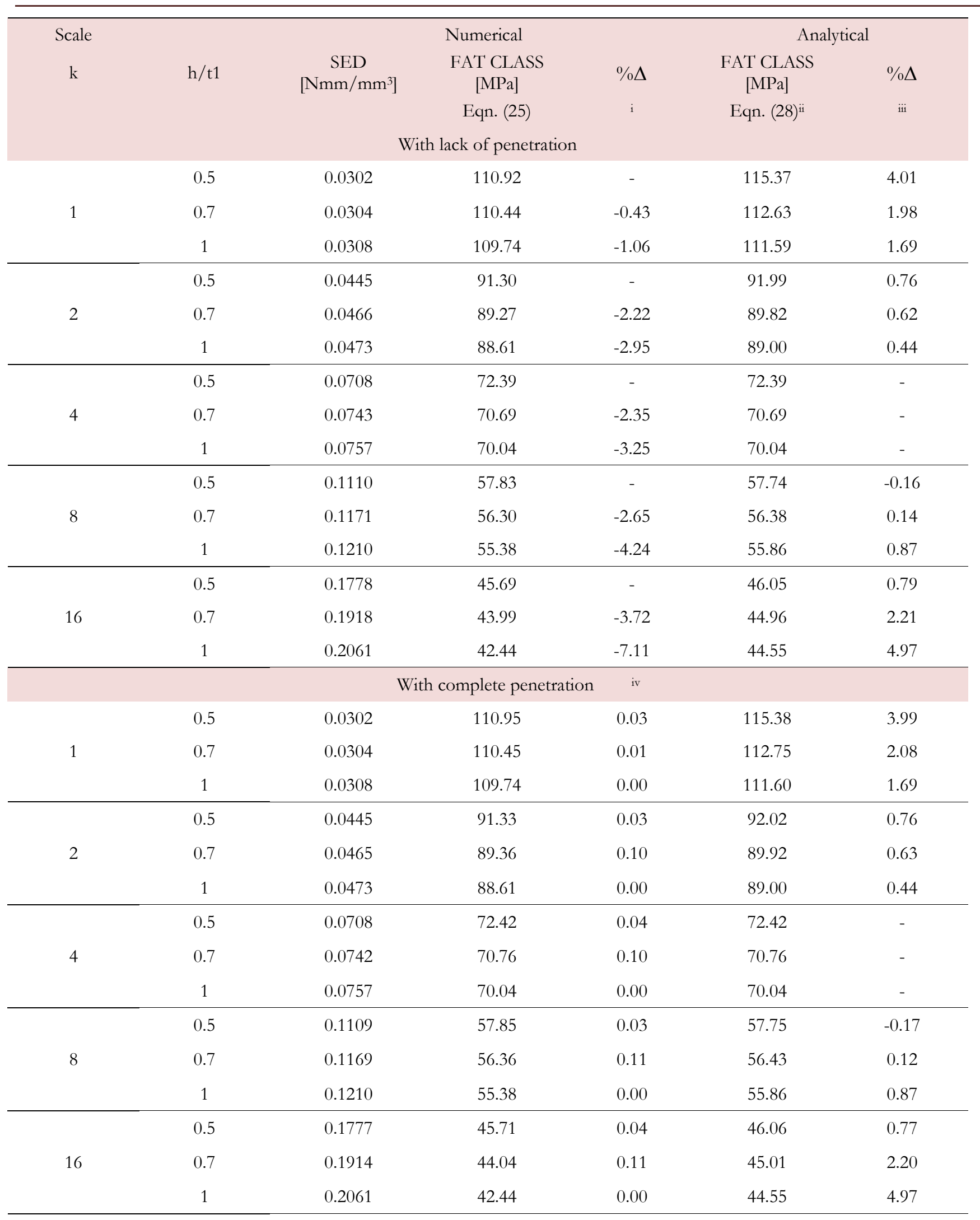

Table 8: Scale effect transverse attachment. 


\begin{tabular}{|c|c|c|c|c|c|c|}
\hline $\mathrm{h} / \mathrm{t} 2$ & Scale & $\mathrm{r} / \mathrm{t} 1$ & $\begin{array}{c}\text { SED } \\
{\left[\mathrm{Nmm} / \mathrm{mm}^{3}\right]}\end{array}$ & $\begin{array}{c}\text { FAT CLASS } \\
{[\mathrm{MPa}]}\end{array}$ & $\% \Delta$ & $\% \Delta$ \\
\hline & $\mathrm{k}$ & & & Eqn. (25) & $\mathrm{v}$ & vi \\
\hline \multirow{12}{*}{0.2} & \multirow{3}{*}{1} & $1 / 6$ & 0.0260 & 74.72 & - & - \\
\hline & & $1 / 4$ & 0.0254 & 75.52 & 1.07 & - \\
\hline & & $1 / 3$ & 0.0251 & 75.94 & 1.63 & - \\
\hline & \multirow{3}{*}{2} & $1 / 6$ & 0.0377 & 61.99 & - & - \\
\hline & & $1 / 4$ & 0.0368 & 62.76 & 1.24 & - \\
\hline & & $1 / 3$ & 0.0364 & 63.10 & 1.79 & - \\
\hline & \multirow{3}{*}{4} & $1 / 6$ & 0.0543 & 51.65 & - & - \\
\hline & & $1 / 4$ & 0.0530 & 52.30 & 1.26 & - \\
\hline & & $1 / 3$ & 0.0524 & 52.62 & 1.88 & - \\
\hline & \multirow{3}{*}{8} & $1 / 6$ & 0.0809 & 42.33 & - & - \\
\hline & & $1 / 4$ & 0.0790 & 42.84 & 1.20 & - \\
\hline & & $1 / 3$ & 0.0780 & 43.11 & 1.84 & - \\
\hline \multirow{12}{*}{0.4} & \multirow{3}{*}{1} & $1 / 6$ & 0.0292 & 70.44 & - & -5.73 \\
\hline & & $1 / 4$ & 0.0293 & 70.38 & -0.09 & -6.81 \\
\hline & & $1 / 3$ & 0.0293 & 70.32 & -0.17 & -7.40 \\
\hline & \multirow{3}{*}{2} & $1 / 6$ & 0.0426 & 58.35 & - & -5.87 \\
\hline & & $1 / 4$ & 0.0427 & 58.29 & -0.10 & -7.12 \\
\hline & & $1 / 3$ & 0.0428 & 58.23 & -0.21 & -7.72 \\
\hline & \multirow{3}{*}{4} & $1 / 6$ & 0.0618 & 48.44 & - & -6.21 \\
\hline & & $1 / 4$ & 0.0620 & 48.37 & -0.14 & -7.51 \\
\hline & & $1 / 3$ & 0.0621 & 48.31 & -0.27 & -8.19 \\
\hline & \multirow{3}{*}{8} & $1 / 6$ & 0.0939 & 39.29 & - & -7.18 \\
\hline & & $1 / 4$ & 0.0942 & 39.24 & -0.13 & -8.40 \\
\hline & & $1 / 3$ & 0.0944 & 39.19 & -0.25 & -9.09 \\
\hline \multirow{12}{*}{0.7} & \multirow{3}{*}{1} & $1 / 6$ & 0.0318 & 67.53 & - & -9.62 \\
\hline & & $1 / 4$ & 0.0325 & 66.80 & -1.08 & -11.55 \\
\hline & & $1 / 3$ & 0.0330 & 66.24 & -1.91 & -12.77 \\
\hline & \multirow{3}{*}{2} & $1 / 6$ & 0.0462 & 56.04 & - & -9.60 \\
\hline & & $1 / 4$ & 0.0472 & 55.43 & -1.09 & -11.68 \\
\hline & & $1 / 3$ & 0.0480 & 54.97 & -1.91 & -12.88 \\
\hline & \multirow{3}{*}{4} & $1 / 6$ & 0.0664 & 46.74 & - & -9.51 \\
\hline & & $1 / 4$ & 0.0678 & 46.23 & -1.09 & -11.61 \\
\hline & & $1 / 3$ & 0.0690 & 45.84 & -1.93 & -12.88 \\
\hline & \multirow{3}{*}{8} & $1 / 6$ & 0.0984 & 38.38 & - & -9.33 \\
\hline & & $1 / 4$ & 0.1006 & 37.96 & -1.09 & -11.39 \\
\hline & & $1 / 3$ & 0.1023 & 37.64 & -1.93 & -12.69 \\
\hline \multirow{12}{*}{1} & \multirow{3}{*}{1} & $1 / 6$ & 0.0333 & 65.98 & - & -11.70 \\
\hline & & $1 / 4$ & 0.0343 & 65.05 & -1.41 & -13.86 \\
\hline & & $1 / 3$ & 0.0351 & 64.32 & -2.52 & -15.30 \\
\hline & \multirow{3}{*}{2} & $1 / 6$ & 0.0483 & 54.79 & - & -11.61 \\
\hline & & $1 / 4$ & 0.0497 & 54.02 & -1.41 & -13.93 \\
\hline & & $1 / 3$ & 0.0508 & 53.42 & -2.50 & -15.34 \\
\hline & \multirow{3}{*}{4} & $1 / 6$ & 0.0692 & 45.78 & - & -11.36 \\
\hline & & $1 / 4$ & 0.0712 & 45.14 & -1.40 & -13.69 \\
\hline & & $1 / 3$ & 0.0728 & 44.64 & -2.49 & -15.17 \\
\hline & \multirow{3}{*}{8} & $1 / 6$ & 0.1014 & 37.81 & - & -10.68 \\
\hline & & $1 / 4$ & 0.1131 & 37.33 & -1.27 & -12.86 \\
\hline & & $1 / 3$ & 0.1067 & 36.86 & -2.51 & -14.50 \\
\hline
\end{tabular}

Table 9: Scale effect for gusset plate welded on the edge of a plate. 


\section{COMPARISON WITH EUROCODE 3}

he design guidance EN 1993-1-9:2005 establishes, for each detail analysed in this work, the rules for the fatigue assessment that were verified in this work through numerical simulations.

As regards the longitudinal joints, the Eurocode 3 establishes four FAT classes that must be chosen according to the value of the parameter called in this work 13 and shown in Fig. 6 a). The results of the numerical simulations in terms of FAT class are reported in Tab. 10 together with the FAT classes established by the design guidance. It is possible to notice that even if there is an improvement in the fatigue strength of the joints with decreasing the parameter 13 this is not enough to explain the increase in fatigue strength expected by the design guidance.

Considering the oblique longitudinal joints, the Eurocode 3 establishes only one FAT class of $71 \mathrm{MPa}$ specifying that the parameter called in this work 15 has to be greater than $100 \mathrm{~mm}$ while the attachment angle must be lower than $45^{\circ}$. Tab. 11 reports for this detail the results of numerical simulations carried out with different values of the attachment angle confirming that the fatigue strength of this joint does not depend on this parameter. Besides the results acquired to investigate the size effect, shown in Tab. 7 , reveal that the fatigue strength of this detail for $\quad l 5>100 \mathrm{~mm}$, as stated by the Eurocode 3, is very lower than the value expected.

As regards the transverse joints, the Eurocode 3 establishes two FAT classes that must be chosen considering the thickness of the joint as a sum of the welding bead thickness and of the attachment thickness. According to the design guidance, the fatigue strength of this detail decreases with increasing the thickness. The results of the numerical simulations, shown in Tab. 12, reveal an opposite behaviour of the fatigue strength with this parameter and, however, the values assessed through the SED method are lower than those expected by the Eurocode.

The influence of the attachment thickness was investigated also for the other joints revealing that, unlike the transverse joints, it has positive effects on the fatigue strength of these details. The results of this analysis are reported in Tab. 13 and 14.

Considering the gusset plate, the Eurocode 3 establishes three FAT classes that must be chosen considering the ratio between the radius of the gusset plate and the main plate width. In particular, it establishes a class of $90 M P a$ for either a ratio greater than $1 / 3$ or for $r>150 \mathrm{~mm}$, a class of $50 \mathrm{MPa}$ for a ratio lower than $1 / 6$ and a class of $71 \mathrm{MPa}$ for a ratio between the first two values. The results reported in Tab. 9 reveal that even if this parameter leads to a benefit on the fatigue strength of the detail this is not enough to explain the increase in the FAT class expected from the design guidance. As stated above for this detail, the welding height is found to be the predominant parameter with respect to the plate fitting radius. The results, reported in Tab. 9, show that the fatigue strength of the detail decrease with increasing the welding height.

\begin{tabular}{|c|c|c|c|c|c|c|}
\hline $\begin{array}{c}11 \\
{[\mathrm{~mm}]}\end{array}$ & $\begin{array}{c}\mathrm{t} 1 \\
{[\mathrm{~mm}]}\end{array}$ & $\begin{array}{c}\mathrm{t} 2 \\
{[\mathrm{~mm}]}\end{array}$ & $\begin{array}{c}13 \\
{[\mathrm{~mm}]}\end{array}$ & $\mathrm{h} / \mathrm{t} 1$ & $\begin{array}{c}\text { FAT CLASS } \\
{[\mathrm{MPa}]} \\
\text { Eqn. (25) }\end{array}$ & $\begin{array}{c}\text { FAT } \\
\text { CLASS } \\
\text { [MPa] } \\
\text { Eurocode 3 }\end{array}$ \\
\hline \multirow[t]{4}{*}{200} & 25 & 25 & 50 & 0.5 & 58.23 & 80 \\
\hline & & & 80 & & 56.22 & 71 \\
\hline & & & 100 & & 55.59 & 63 \\
\hline & & & 150 & & 53.97 & 56 \\
\hline
\end{tabular}

Table 10: Comparison between numerical assessed FAT and FAT established by Eurocode 3 for longitudinal joint.

\begin{tabular}{|c|c|c|c|c|c|c|c|}
\hline $\begin{array}{c}11 \\
{[\mathrm{~mm}]}\end{array}$ & $\begin{array}{c}\mathrm{t} 1 \\
{[\mathrm{~mm}]}\end{array}$ & $\begin{array}{c}\mathrm{t} 2 \\
{[\mathrm{~mm}]}\end{array}$ & $\begin{array}{c}13 \\
{[\mathrm{~mm}]}\end{array}$ & $\begin{array}{c}15 \\
{[\mathrm{~mm}]}\end{array}$ & $\mathrm{h} / \mathrm{t} 1$ & $\begin{array}{c}\text { Alfa } \\
\left.{ }^{\circ}\right]\end{array}$ & $\begin{array}{c}\text { FAT } \\
\text { CLASS } \\
{[\mathrm{MPa}]} \\
\text { Eqn. (25) }\end{array}$ \\
\hline 200 & 25 & 25 & 50 & 55 & 0.5 & $\begin{array}{l}20 \\
30 \\
35 \\
40\end{array}$ & $\begin{array}{l}55.51 \\
55.41 \\
55.34 \\
55.23\end{array}$ \\
\hline
\end{tabular}

Table 11: Comparison between numerical assessed FAT and FAT established by Eurocode 3 for oblique longitudinal joint. 


\begin{tabular}{|c|c|c|c|c|c|c|}
\hline $\begin{array}{c}11 \\
{[\mathrm{~mm}]}\end{array}$ & $\begin{array}{c}\mathrm{t} 1 \\
{[\mathrm{~mm}]}\end{array}$ & $\begin{array}{c}\mathrm{t} 2 \\
{[\mathrm{~mm}]}\end{array}$ & $\begin{array}{c}13 \\
{[\mathrm{~mm}]}\end{array}$ & $\mathrm{h} / \mathrm{t} 1$ & $\begin{array}{c}\text { FAT CLASS } \\
{[\mathrm{MPa}]} \\
\text { Eqn. (25) }\end{array}$ & $\begin{array}{c}\text { FAT } \\
\text { CLASS } \\
{[\mathrm{MPa}]} \\
\text { Eurocode } 3\end{array}$ \\
\hline \multirow[t]{3}{*}{200} & 25 & 12.5 & 50 & 1 & 63.38 & 71 \\
\hline & & 25 & & & 62.15 & 80 \\
\hline & & 50 & & & 60.34 & 80 \\
\hline
\end{tabular}

Table 12: Comparison between numerical assessed FAT and FAT established by Eurocode 3 for transverse joint.

\begin{tabular}{|c|c|c|c|c|c|c|c|}
\hline $\begin{array}{c}11 \\
{[\mathrm{~mm}]}\end{array}$ & $\begin{array}{c}\mathrm{t} 1 \\
{[\mathrm{~mm}]}\end{array}$ & $\begin{array}{c}\mathrm{t} 2 \\
{[\mathrm{~mm}]}\end{array}$ & $\begin{array}{c}13 \\
{[\mathrm{~mm}]}\end{array}$ & $\begin{array}{c}15 \\
{[\mathrm{~mm}]}\end{array}$ & $\mathrm{h} / \mathrm{t} 1$ & $\begin{array}{c}\text { Alfa } \\
{\left[{ }^{\circ}\right]}\end{array}$ & $\begin{array}{c}\text { FAT } \\
\text { CLASS } \\
\text { [MPa] } \\
\text { Eqn. (25) }\end{array}$ \\
\hline \multirow[t]{3}{*}{200} & 25 & 12.5 & 50 & 55 & 1 & 44 & 56.74 \\
\hline & & 25 & & & & & 58.63 \\
\hline & & 50 & & & & & 60.94 \\
\hline
\end{tabular}

Table 13: Effect of the attachment thickness for oblique longitudinal joint.

\begin{tabular}{cccccc}
\hline 11 & $\mathrm{t} 1$ & $\mathrm{t} 2$ & 13 & $\mathrm{~h} / \mathrm{t} 1$ & $\begin{array}{c}\text { FAT CLASS } \\
{[\mathrm{MPa}]}\end{array}$ \\
{$[\mathrm{mm}]$} & {$[\mathrm{mm}]$} & {$[\mathrm{mm}]$} & {$[\mathrm{mm}]$} & Eqn. $(25)$ \\
& & & 50 & 57.12 & 59.23 \\
& 25 & 12.5 & & 62.28 \\
\hline
\end{tabular}

Table 14: Effect of the attachment thickness for longitudinal joint.

\section{CONCLUSIONS}

$\mathrm{I}$

$\mathrm{n}$ this paper, we investigated, by means of numerical simulations, the fatigue strength of weld attachments and stiffeners through the SED method. The results of the FE simulations reveal that:

- There is good agreement between analytical and numerical results for longitudinal and transverse joints. In this case, the scale effect can be considered through Eqn. (28) using $\lambda_{1}=0.6736$ according to Williams' theory.

- The scale effect for the gusset plate can be considered through Eqn. (28) considering an exponent equals to -0.267 .

- As regards longitudinal and transverse joints, the assessed FAT class of the joints increases with increasing the welding height. However, the relative deviation $\% \Delta$ is always lower than $3.5 \%$.

- As regards the gusset plate, the fatigue strength decreases with increasing the welding height. The relative deviation $\% \Delta$ for the cases analysed can reach also a value of $-15 \%$. It was found that for a ratio $h / t<0.4$ the fatigue strength of the detail is no longer influenced by the welding height. Below this value of the ratio $b / t$, the increase in fatigue strength that is possible to evaluate from the results has to be referred only to the different values of the attachment fitting radius.

- Even if the complete penetration leads to an effective benefit on the fatigue strength, it is always lower than $1 \%$ referring to the equivalent case with lack of penetration. Besides, the numerical simulations reveal that the benefit increases with decreasing the welding height. 
- The Eurocode 3 appears to overestimate the fatigue strength of the details analysed and to neglect some parameters that, instead, reveal an important influence on the fatigue strength.

\section{REFERENCES}

[1] Fricke, W. (2013). IIW guideline for the assessment of weld root fatigue, Weld. World, 57(6), pp. 753-91. DOI: $10.1007 /$ s40194-013-0066-y.

[2] 1993-1-3:2009, B.E. (2011). Eurocode 3: Design of steel structures - Part 1-9: Fatigue. Eurocode 3: Design of steel structures - Part 1-9: Fatigue, 7.

[3] Hobbacher, A. (2016). Recommendations for Fatigue Design of Welded Joints and Components.

[4] Radaj, D., Sonsino, C.M., Fricke, W. (2009). Recent developments in local concepts of fatigue assessment of welded joints, Int. J. Fatigue, 31(1), pp. 2-11. DOI: 10.1016/j.ijfatigue.2008.05.019.

[5] Fricke, W., Kahl, A. (2005). Comparison of different structural stress approaches for fatigue assessment of welded ship structures, Mar. Struct., 18(7-8), pp. 473-488. DOI: 10.1016/j.marstruc.2006.02.001.

[6] Radaj, D., Sonsino, C.M., Fricke, W. (2006). Fatigue Assessment of Welded Joints by Local Approaches: Second Edition.

[7] Lazzarin, P., Livieri, P., Berto, F., Zappalorto, M. (2008). Local strain energy density and fatigue strength of welded joints under uniaxial and multiaxial loading, Eng. Fract. Mech., 75(7), pp. 1875-1889. DOI: $10.1016 /$ j.engfracmech.2006.10.019.

[8] Lazzarin, P., Zambardi, R. (2001). A finite-volume-energy based approach to predict the static and fatigue behavior of components with sharp V-shaped notches, Int. J. Fract., 112(3), pp. 275-298. DOI: 10.1023/ A:1013595930617.

[9] Lazzarin, P., Zambardi, R. (2002). The equivalent strain energy density approach re-formulated and applied to sharp Vshaped notches under localized and generalized plasticity, Fatigue Fract. Eng. Mater. Struct., 25(10), pp. 917-928. DOI: 10.1046/j.1460-2695.2002.00543.x.

[10] Beltrami, E. (1885). Sulle condizioni di resistenza dei corpi elastici, Nuovo Cim., 18(1), pp. $145-155$. DOI: $10.1007 / \mathrm{BF} 02824697$.

[11] Neuber, H. (1958). Kerbspannungslehre: Grundlagen für genaue Festigkeitsberechnung mit Berücksichtigung von Konstruktionsform und Werkstoff.

[12] Neuber, H. (1968). Über die Berücksichtigung der Spannungskonzentration bei Festigkeitsberechnungen, Konstruktion, 20(7), pp. 245-251.

[13] Neuber, H. (1985). Kerbspannungslehre: Grundlagen für genaue Spannungkonzentration.

[14] Sheppard, S.D. (1991). Filed effects in fatigue crack initiation: long life fatigue strength, Trans. ASME, 113(June 1991), pp. 188-194. DOI: $10.1002 /$ jcop. 21900.

[15] Sonsino, C.M. (1995). Multiaxial fatigue of welded joints under in-phase and out-of-phase local strains and stresses, Int. J. Fatigue, 17(1), pp. 55-70. DOI: 10.1016/0142-1123(95)93051-3.

[16] Taylor, D. (2000). Geometrical effects in fatigue: a unifying theoretical model, Int. J. Fatigue, 21(5), pp. 413-420. DOI: 10.1016/S0142-1123(99)00007-9.

[17] Erdogan, F., Sih, G.C. (1963). On the Crack Extension in Plates Under Plane Loading and Transverse Shear, J. Basic Eng., 85(4), pp. 519. DOI: 10.1115/1.3656897.

[18] Sih, G.C. (1974). Strain-energy-density factor applied to mixed mode crack problems, Int. J. Fract., 10(3), pp. 305-21, DOI: $10.1007 /$ BF00035493.

[19] G.C. Sih. (1974). Surface Layer Energy and Strain Energy Density for a Blunted Crack or Nothc, Prospect. Fract. Mech., (1974), pp. 85-102.

[20] Sih, G.C. (1991). A special theory of crack propagation. Mechanics of Fracture Initiation and Propagation: Surface and volume energy density applied as failure criterion, Dordrecht, Springer Netherlands, pp. 1-22.

[21] Molski, K., Glinka, G. (1981). A method of elastic-plastic stress and strain calculation at a notch root, Mater. Sci. Eng., 50(1), pp. 93-100. DOI: 10.1016/0025-5416(81)90089-6.

[22] Berto, F., Lazzarin, P. (2009). A review of the volume-based strain energy density approach applied to V-notches and welded structures, Theor. Appl. Fract. Mech., 52(3), pp. 183-194. DOI: 10.1016/j.tafmec.2009.10.001.

[23] Williams, M.L. (1952). Stress singularities resulting from various boundary conditions, J. Appl. Mech., 19(4), pp. 526528. DOI: $10.1115 / 1.321174$.

[24] Gross, B., Mendelson, A. (1972). Plane elastostatic analysis of V-notched plates, Int. J. Fract. Mech., 8(3), pp. 267-276. DOI: $10.1007 / \mathrm{BF} 00186126$. 
[25] Radaj, D., Vormwald, M. (2013). Advanced methods of fatigue assessment, 9783642307.

[26] Radaj, D., Berto, F., Lazzarin, P. (2009). Local fatigue strength parameters for welded joints based on strain energy density with inclusion of small-size notches, Eng. Fract. Mech., 76(8), pp. 1109-1130. DOI: 10.1016/j.engfracmech.2009.01.009.

[27] Radaj, D. (2015). State-of-the-art review on the local strain energy density concept and its relation to the J-integral and peak stress method, Fatigue Fract. Eng. Mater. Struct., 38(1), pp. 2-28. DOI: 10.1111/ffe.12231.

[28] Lazzarin, P., Berto, F. (2005). Some expressions for the strain energy in a finite volume surrounding the root of blunt V-notches, Int. J. Fract., 135(1-4), pp. 161-185. DOI: 10.1007/s10704-005-3943-6.

[29] Lazzarin, P., Berto, F. (2005). From Neuber's elementary volume to Kitagawa and Atzori's diagrams: An interpretation based on local energy, Int. J. Fract., 135(1-4), pp. 33-3., DOI: 10.1007/s10704-005-4393-x.

[30] Yosibash, Z., Bussiba, A., Gilad, I. (2004). Failure criteria for brittle elastic materials, Int. J. Fract., 125(1957), pp. 307333. DOI: $10.1007 / 978-1-4614-1508-4$.

[31] Lazzarin, P., Sonsino, C.M., Zambardi, R. (2004). A notch stress intensity approach to assess the multiaxial fatigue strength of welded tube-to-flange joints subjected to combined loadings, Fatigue Fract. Eng. Mater. Struct., 27(2), pp. 127-140. DOI: 10.1111/j.1460-2695.2004.00733.x.

[32] Lazzarin, P., Berto, F., Gomez, F.J., Zappalorto, M. (2008). Some advantages derived from the use of the strain energy density over a control volume in fatigue strength assessments of welded joints, Int. J. Fatigue, 30(8), pp. 1345-1357. DOI: 10.1016/j.ijfatigue.2007.10.012.

[33] Filippi, S., Lazzarin, P., Tovo, R. (2002). Developments of some explicit formulas useful to describe elastic stress fields ahead of notches in plates, Int. J. Solids Struct., 39(17), pp. 4543-4565. DOI: 10.1016/S0020-7683(02)00342-6.

[34] Gómez, F.J., Elices, M., Berto, F., Lazzarin, P. (2009). Fracture of U-notched specimens under mixed mode: Experimental results and numerical predictions, Eng. Fract. Mech., 76(2), pp. 236-249.

DOI: 10.1016/j.engfracmech.2008.10.001.

[35] Berto, F., Lazzarin, P., Marangon, C. (2012). Brittle fracture of U-notched graphite plates under mixed mode loading, Mater. Des., 41(2012), pp. 421-432. DOI: 10.1016/j.matdes.2012.05.022.

[36] Lazzarin, P., Berto, F., Ayatollahi, M.R. (2013). Brittle failure of inclined key-hole notches in isostatic graphite under inplane mixed mode loading, Fatigue Fract. Eng. Mater. Struct., 36(9), pp. 942-955. DOI: 10.1111/ffe.12057.

[37] Gómez, F.J., Elices, M., Berto, F., Lazzarin, P. (2007). Local strain energy to assess the static failure of U-notches in plates under mixed mode loading, Int. J. Fract., 145(1), pp. 29-45. DOI: 10.1007/s10704-007-9104-3.

[38] Berto, F., Lazzarin, P., Gómez, F.J., Elices, M. (2007). Fracture assessment of U-notches under mixed mode loading: Two procedures based on the "equivalent local mode I" concept, Int. J. Fract., 148(4), pp. 415-433.

DOI: $10.1007 / \mathrm{s} 10704-008-9213-7$.

[39] Gómez, F.J., Elices, M., Berto, F., Lazzarin, P. (2008). A generalised notch stress intensity factor for U-notched components loaded under mixed mode, Eng. Fract. Mech., 75(16), pp. 4819-4833.

DOI: 10.1016/j.engfracmech.2008.07.001.

[40] Berto, F., Elices, M., Lazzarin, P., Zappalorto, M. (2012). Fracture behaviour of notched round bars made of PMMA subjected to torsion at room temperature, Eng. Fract. Mech., 90, pp. 143-160.

DOI: 10.1016/j.engfracmech.2012.05.001.

[41] Berto, F., Cendon, D.A., Lazzarin, P., Elices, M. (2013). Fracture behaviour of notched round bars made of PMMA subjected to torsion at $-60^{\circ} \mathrm{C}$, Eng. Fract. Mech., 102(2013), pp. 271-287. DOI: 10.1016/j.engfracmech.2013.02.011.

[42] Berto, F. (2015). A criterion based on the local strain energy density for the fracture assessment of cracked and Vnotched components made of incompressible hyperelastic materials, Theor. Appl. Fract. Mech., 76, pp. 17-26. DOI: $10.1016 /$ j.tafmec.2014.12.008.

[43] Lazzarin, P., Berto, F., Zappalorto, M. (2010). Rapid calculations of notch stress intensity factors based on averaged strain energy density from coarse meshes: Theoretical bases and applications, Int. J. Fatigue, 32(10), pp. 1559-1567. DOI: $10.1016 /$ j.ijfatigue.2010.02.017.

[44] Lazzarin, P., Livieri, P. (2001). Notch stress intensity factors and fatigue strength of aluminium and steel welded joints, Int. J. Fatigue, 23, pp. 225-232. DOI: 10.1016/S0142-1123(00)00086-4.

[45] Lazzarin, P., Lassen, T., Livieri, P. (2003). A notch stress intensity approach applied to fatigue life predictions of welded joints with different local toe geometry, Fatigue Fract. Eng. Mater. Struct., 26(1), pp. 49-58. DOI: 10.1046/j.1460-2695.2003.00586.x.

[46] Livieri, P., Lazzarin, P. (2005). Fatigue strength of steel and aluminium welded joints based on generalised stress intensity factors and local strain energy values, Int. J. Fract., 133(3), pp. 247-276. DOI: 10.1007/s10704-005-4043-3. 
[47] Atzori, B., Berto, F., Lazzarin, P., Quaresimin, M. (2006). Multi-axial fatigue behaviour of a severely notched carbon steel, Int. J. Fatigue, 28(5-6), pp. 485-493. DOI: 10.1016/j.ijfatigue.2005.05.010.

[48] Berto, F., Lazzarin, P. (2011). Fatigue strength of structural components under multi-axial loading in terms of local energy density averaged on a control volume, Int. J. Fatigue, 33(8), pp. 1055-1065. DOI: $10.1016 /$ j.ijfatigue.2010.11.019.

[49] Berto, F., Lazzarin, P. (2014). Recent developments in brittle and quasi-brittle failure assessment of engineering materials by means of local approaches, Mater. Sci. Eng. R Reports, 75(1), pp. 1-48. DOI: 10.1016/j.mser.2013.11.001.

[50] Atzori, B., Demelio, G., Rossi, B. (2009). Effetto delle dimensioni del cordone di saldatura sulla resistenza a fatica dei giunti a croce, Riv. Ital. Della Saldatura, 61(4), pp. 447-455. DOI: 10.3221/IGF-ESIS.09.03.

[51] Balasubramanian, V., Guha, B. (1999). Effect of weld size on fatigue crack growth behaviour of cruciform joints by strain energy density factor approach, Theor. Appl. Fract. Mech., 31(2), pp. 141-148.

DOI: 10.1016/S0167-8442(99)00008-7.

\footnotetext{
i The model with ratio $h / t 1=0.5$ being the reference case.

ii The model with $k=4$ being the reference case to assess the FAT classes for the other model in geometrical proportion.

iii The FAT class assessed by Eqn. (25) being the reference case.

iv The corresponding case with lack of penetration being the reference case.

v The model with ratio $r / l=1 / 6$ being the reference case.

vi The model with a ratio $b / t=0.2$ being the reference case
} 